\title{
Psychometric Properties of the Wake Forest Physician Trust Scale with Young and Older Adults
}

\author{
Emma Katz
}

Follow this and additional works at: https://researchrepository.wvu.edu/etd

Part of the Psychology Commons

\section{Recommended Citation}

Katz, Emma, "Psychometric Properties of the Wake Forest Physician Trust Scale with Young and Older Adults" (2018). Graduate Theses, Dissertations, and Problem Reports. 5942.

https://researchrepository.wvu.edu/etd/5942

This Thesis is protected by copyright and/or related rights. It has been brought to you by the The Research Repository @ WVU with permission from the rights-holder(s). You are free to use this Thesis in any way that is permitted by the copyright and related rights legislation that applies to your use. For other uses you must obtain permission from the rights-holder(s) directly, unless additional rights are indicated by a Creative Commons license in the record and/ or on the work itself. This Thesis has been accepted for inclusion in WVU Graduate Theses, Dissertations, and Problem Reports collection by an authorized administrator of The Research Repository @ WVU. For more information, please contact researchrepository@mail.wvu.edu. 
Psychometric Properties of the Wake Forest Physician Trust Scale With Young and Older Adults

$$
\text { Emma Katz, B.A. }
$$

Thesis submitted to the Eberly College of Arts and Sciences at West Virginia University in partial fulfillment of the requirements for the degree of

Master of Science in Psychology

Barry Edelstein, Ph.D., Chair

Nicholas A. Turiano, Ph.D.

Amy Fiske, Ph.D.

Department of Psychology

Morgantown, West Virginia

2018

Keywords: Patient-physician trust, psychometrics, trust scale

Copyright 2018 Emma Katz 


\begin{abstract}
Psychometric Properties of the Wake Forest Physician Trust Scale With Young and Older Adults
\end{abstract}

\author{
Emma Katz
}

Trust is an essential component of any interpersonal relationship, but it is particularly integral to the patient-physician relationship. Patient-physician trust increases willingness to seek treatment, disclose sensitive information, adhere to medical recommendations, and share decision-making authority. While there have been developments in current research on the psychosocial variables associated with patient-physician trust, there continues to be the need for a psychometrically sound measure of trust, as well as a further need for psychometric evaluation of already developed measures. The purpose of the study was to reexamine a measure of patientphysician trust, the Wake Forest Physician Trust Scale (WFPTS), using more properly selected measures to obtain convergent and discriminant validity evidence as well as reliability evidence. Although the WFPTS was chosen due to its appropriate and comprehensive scale development process, construct validity evidence with an adult population was questionable and there was no reported validity and/or reliability evidence for an older adult population. Three hundred and forty English-speaking, community-dwelling adults were recruited to participate in this study. Data was collected with the WFPTS and measures of trustworthiness, patient satisfaction, decision-making, health locus of control, confidentiality, health, personality traits, and physician empathy to gather validity evidence for the WFPTS with adult and older adult samples.

Measures of internal consistency also were obtained. Scores of the WFPTS exhibited satisfactory internal consistency and good convergent validity with significant, moderate to strong correlations with both the young adult and older adult samples. Discriminant validity evidence was also demonstrated with each age group based on weak relations with a measure of openness to experience. Findings from this study provide support for the psychometric properties of the WFPTS with young and older adult populations. These results also confirm the validity of data obtained with the WFPTS with young adults and provide support for the use of this instrument with older adults. Future directions for research with this instrument are discussed. 


\section{Acknowledgments}

I would like to thank my advisor and committee chair, Barry Edelstein, Ph.D., for his neverending guidance, patience, edits, and knowledge. Many thanks to Nicholas Turiano, Ph.D. and Amy Fiske, Ph.D. for serving as members of my committee and for all their advice and feedback throughout this process.

Finally, I would like to thank my parents, Rob and Sherrill, sister, Zoe, and boyfriend, Dmitriy, for their unwavering love, humor, and support. I am a better me because of all of you. 


\section{Table of Contents}

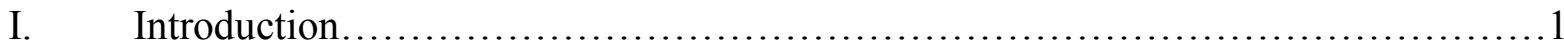

a. Interpersonal Trust.................................................

b. Factors Associated with Patient-Physician Trust.............................4

c. Current Trust Assessment Instruments.................................... 8

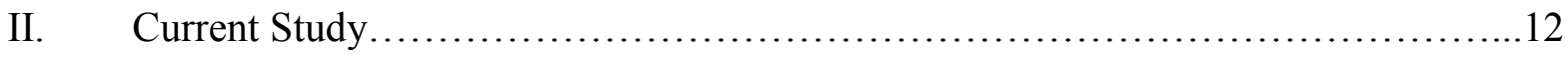

a. Statement of Problem.................................................... 12

b. Research Aims and Hypotheses........................................... 14

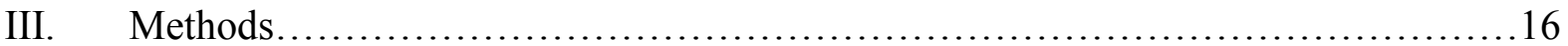

a. Participants and Sample Size......................................... 16

b. Measures................................................................... 17

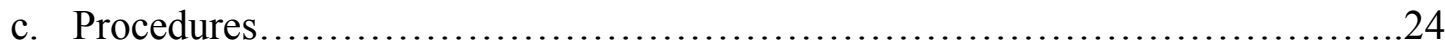

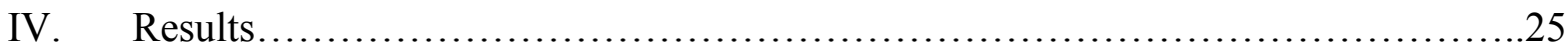

a. Sample Characteristics.............................................25

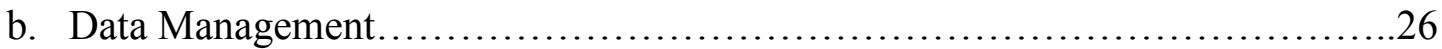

c. Aim 1: Construct Validity............................................. 27

d. Aim 2: Discriminant Validity....................................... 28

e. Aim 3: Reliability..................................................29

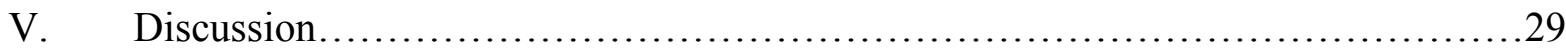

VI. References........................................................ 37

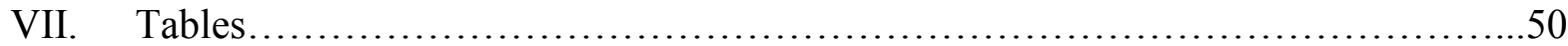

VIII. Appendices

a. Appendix A.......................................................... 54

b. Appendix B.......................................................... 55

c. Appendix C..................................................... 56

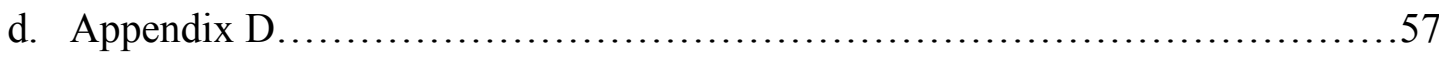

e. Appendix E........................................................ 58

f. Appendix F......................................................... 59

g. Appendix G....................................................61

h. Appendix H.....................................................62 
Psychometric Properties of the Wake Forest Physician Trust Scale With Young and Older Adults

\section{Introduction}

\section{Interpersonal Trust}

In recent years, the construct of trust has generated increased interest within the medical field (e.g. Thom, Hall, \& Pawlson, 2004; Freburger et al., 2003; Pearson \& Raeke, 2000; Goold \& Lipkin, 1999). Trust between any two people necessitates a prediction about future behavior together (Mishra, 1996). Trust is defined as the "assured reliance on the character, ability, strength, or truth of someone or something" (Merriam-Webster, n.d., Accessed April 8, 2017). There is an element of vulnerability involved in trust, as trust involves taking a risk that the trustee will perform a valued behavior (Mayer, Davis, \& Schoorman, 1995). Thus, trust can be viewed as the acceptance of this vulnerable situation in which the "truster" believes that the trustee will act in the "truster's" best interests (Thom, Hall, \& Pawlson, 2004).

Within the physician trust literature, a distinction between social and interpersonal trust has been made (Mechanic \& Schlesinger, 1996). Social trust refers to trust in the healthcare system as a whole, which can be influenced by the media and by general social confidence in particular institutions. Interpersonal trust is the trust in the individual's health care provider, built through repeated interaction in which expectations of the provider's trustworthiness can be tested over time (Pearson \& Raeke, 2000). Interpersonal trust between patient and physician has been defined as the optimistic acceptance of a vulnerable situation in which the patient believes the physician will care for the interest of the patient (Hall, Dugan, Zheng, \& Mishra, 2001). Some theorists have suggested that physician trust is the reassuring feeling of confidence or reliance on the physician and the physician's intent (Caterinicchio, 1979). 
Trust is a principal component of any interpersonal relationship, but it is particularly essential to the patient-physician relationship (Pearson \& Raeke, 2000). Patient trust is an intricate, multidimensional construct, which can impact the patient's relationship with his or her physician as well as the treatment process. The perception of trust between patient and physician has been associated with better communication, patient compliance with medical regimens, and an increase in collaborative decision-making (Thom, Hall, \& Pawlson, 2004). Additionally, changing health care reform legislation, levying of significant cost control, and the expansion of managed care, continue to highlight the need to better comprehend and preserve the patientphysician relationship (Thom, Hall, \& Pawlson, 2004). Research on the erosion of patients' trust in their health providers and physicians has linked this erosion to managed care (Davis \& Rundall, 2000; Mechanic, 1996). Structural arrangements and utilization reviews within managed care may potentially challenge patients' trust in their physician, as these have the capability to restrict choice, and restrict open communication between patient and physician (Mechanic \& Schlesinger, 1996). Thom, Hall, and Pawlson also suggest that patient trust can be considered a collective good, like social capital, that ultimately benefits the medical relationship and is necessary for an effective health care system to operate (2004). There is a persistent need to study trust between patient and physician, and to better understand the factors that are associated with trusting relationships within medical settings.

Recent interest in trust relationships has generated a closer look at the importance of patient-physician relationships in effective medical care (Davis \& Rundall, 2000). The most common domains of physicians' behavior on which patients are believed to base their trust are technical competency (e.g. thoroughness in evaluation and providing appropriate and effective treatment), interpersonal competency (e.g. communicating clearly, understanding patient's 
individual experience, and honesty and respect for the patient), dependability, and compassion (Trachtenberg, Dugan, \& Hall, 2005; Thom, Hall, \& Pawlson, 2004; Mechanic \& Schlesinger, 1996; Emanuel \& Dubler, 1995). Hall and colleagues condensed these domains to develop a five-part conceptual model of trust consisting of 1) fidelity (pursuing a patient's best interest and not taking advantage of their vulnerability), 2) competence (avoiding making mistakes to produce the best achievable result), 3) honesty (telling the truth and avoiding intentional lies), 4) confidentiality (protection and proper use of patient information), and 5) global trust (Hall, Dugan, Zheng, \& Mishra, 2001).

Relationships based on trust between physicians and patients have an important role in successful healthcare. Patients with higher levels of trust are more willing to disclose sensitive information to a physician and are less likely to want to verify physician's recommendations, reducing the costs associated with getting second opinions (e.g. Thom, Hall, \& Pawlson, 2004; Berrios-Riveria et al., 2006; Julliard et al., 2008). Trust is also a strong predictor of continuity with providers. Patients with higher levels of trust in their physician are less likely to change providers. Patients with lower levels of trust also report being less satisfied with their care, less likely to plan on following the physicians' advice, and less likely to report improvement in their symptoms in the following two weeks (Thom et al, 2002). Additionally, patients with low levels of trust are more likely to report that needed or requested medical services were not provided during the visit with their physician (Thom et al., 2002). One study found that the most significant predictor of patients' preferred role in medical care is their trust in the medical profession (Trachtenberg, Dugan, \& Hall, 2005). The authors of this study also established that a patient's greater trust in his or her physician is correlated with a greater willingness to seek treatment when treatment is needed, to follow the recommendations put forth by the physicians, 
and to grant the physicians decisional authority (Trachtenberg, Dugan, \& Hall, 2005).

Additionally, a patient who trusts his or her physician is more likely to return for follow up care appointments (Trachtenberg, Dugan, \& Hall, 2005). Mistrust in physicians is associated with poorer health habits, (Harju, Wuensch, Kuhl, \& Cross, 2006), delayed checkups (Hammond el al., 2010), missed appointments (Siminoff, Hausmann, \& Ibrahim, 2008), and unmet medical needs (Mollborn et al., 2005).

While trust can be a positive construct in terms of strengthening the relationship between a patient and his or her physician, more trust is not necessarily better. Individuals who exhibit high levels of trust may be more likely to trust a person without clear evidence that they can in fact be trusted (Rotter, 1980). Although this could allow the patient to extend good faith to a new physician, the potential differential in power between a patient and doctor may put the patient in a more vulnerable position in the relationship going forward (Goold \& Lipkin, 1999). Patients who trust their physicians desire less input in the decision making process (Arora \& McHorney, 2000), which could potentially cause them to accept a physician's treatment suggestions as indisputable or the only option instead of conversing about additional options if they would so desire.

\section{Factors Associated with Patient-Physician Trust}

Interpersonal trust is a particularly significant aspect of a successful patient-physician relationship. This study is focused on the assessment of patient-physician trust, and a variety of important healthcare-related variables have been examined with regard to their relation to patient trust. One important factor associated with trust between patient and physician is patient satisfaction. Patient satisfaction ratings are a key indicator of quality of care (Kong et al., 2007; Epstein, Lee, \& Hamel, 2004). Patient satisfaction refers to a patient's opinion of his or her 
physician's actions and refers to the act of looking backwards at past experiences (Thom, Hall, \& Pawlson, 2004). Many studies have demonstrated a relation between patient-physician trust and patient satisfaction (Thom et al., 2002; Safran et al., 1998; Platonova, Kennedy, \& Shewchuk, 2008; Weng, 2008). Trusting patients are more likely to report being satisfied and previous good encounters are likely to foster greater trust (Hall et al., 2001). For example, Thom and colleagues (2002) found that patients with low levels of trust reported being less satisfied with their care and less likely to follow their doctor's advice. Safran and colleagues studied Commonwealth of Massachusetts employees to better understand the relation between patients and primary care performance including the role trust has in treatment. In their study of 7,204 participants, trust was reported as the variable most strongly associated with patients' satisfaction with their physician (1998). Patient satisfaction also plays an important moderating role in increasing the strength of the association between patient trust in their healthcare service provider and overall healthcare quality (Alrubaiee \& Alkaa'ida, 2011).

There is increasing evidence that patient trust is associated with patient adherence to treatment recommendations (e.g., Thom et al, 1999; Thom, Hall, \& Pawlson, 2004; Trachtenberg, Dugan, \& Hall, 2005). Many studies have reported that greater trust in physicians is associated with greater adherence to treatment and better self-management of illnesses (e.g., Thom, Hall, \& Pawlson, 2004; Trachtenberg, Dugan, \& Hall, 2005, Salkend, 2004; Piette, Heilser, \& Krein, 2005). Salkend and colleagues (2004) found that a sense of trust in cancer patients' physicians was related to the patients' willingness to accept and adhere to their physicians' advice during diagnosis and treatment. High levels of trust are also associated with increased utilization of preventative screenings (Musa et al., 2009). Furthermore, high levels of continuity of patients' staying with their physicians is associated with decreased likelihood of 
future hospitalization and decreased emergency department use due to high rates of adherence to treatment plans (Mainous et al., 2001; Ionescu-Ittu et al., 2007). Additionally, patients with high out-of-pocket medication costs are often more likely to forgo medications due to cost pressures, yet a trusting physician-patient relationship can moderate the impact of cost pressures on patients' adherence to medication (Piette, Heilser, \& Krein, 2005). Thom and colleagues (1999) found that patients in the highest quartile of trust in the study reported that they followed their doctor's recommendation and always took their prescribed medication, compared with those in the lowest trust quartile who did not.

Another important variable associated with patient-physician trust is empathy. Empathy within the context of patient care in the medical setting can be defined as an understanding of patients' concerns, perspectives, and experiences intertwined with a capacity to communicate this understanding, and an intention to help the patient in question (Hojat, 2007; Hojat et al., 2009). Empathy helps enhance patient-physician communication, treatment effectiveness, and trust (Halpern, 2003). When physicians are aware of their patients' nonverbal cues (e.g. vocal tones, body language), patients report feeling more comfortable and giving fuller medical histories (Suchman et al., 1997). Tulsky et al. (2011) administered an interactive course to oncologists on empathy to assess enhanced communication between oncologists and patients. They found that doctors who took the empathy course inspired greater trust in their patients than those who did not.

Shared medical decision-making is another variable related to patient-physician trust, and for which there has been a strong push in recent years in the medical community (e.g. Lee \& Emanuel, 2013). Shared decision making is a crucial component of the patient-physician relationship, and the most significant predictor of a patient's preferred role in medical decision 
making is trust in the physician (Trachtenberg, Dugan, \& Hall, 2005; Kraetschmer et al., 2004). Shared decision-making is the process of healthcare decisions being made through the collaboration between the physician and patient (Stacey et al., 2014). It contributes to informed choices and supports patient autonomy (Elywyn, 2012). Physicians' shared decision-making behaviors are viewed as facilitations of patient trust, which is enhanced when physicians provide more information to patients about test results and general information about their health and when physicians discuss risks and benefits of various treatment options (Peek et al., 2013). Patients with greater levels of trust in their physicians desire less control over decision-making during visits than those patients with lower levels of trust (Arora \& McHorney, 2000). Increased trust is associated with patients feeling well informed about decision-making procedures involving cancer screening decision, medication decisions, and surgery decisions (Sepucha et al., 2010).

Age is a final variable related to patient-physician trust. Older adults report higher levels of trust in their physicians than their younger adult counterparts (e.g. Boyd et al, 2008; Mainous et al., 2001; Simon, Zang, \& Dong, 2014). This may be due to older adult's increased interactions with health care providers because of multiple chronic or comorbid health conditions (Bell et al., 2013) or perhaps with older age comes more time to establish a trusting relationship with their physician. A trusting partnership between an older adult patient and a physician is important for successful aging and better disease management (Mascarenhas et al, 2006). Older adults report that they need to first trust their physician before discussing the patient's goals and participate in future goal planning (Schulman-Green et al., 2005). Older adults also report higher levels of trust in their physicians, and there is evidence that such trust increases across the 
lifespan (Poulin \& Haase, 2015), therefore better understanding about trust between older patients and physicians is crucial to continue examining.

Many important healthcare outcomes are associated with patients' trust of physicians. Nevertheless, the validity of these findings rests on the validity and reliability of the measures used to assess trust. In view of that, currently used patient trust assessment instruments will be briefly reviewed with an eye to the adequacy of their psychometric properties.

\section{Current Trust Assessment Instruments}

There have been a variety of measures of patient-physician trust that have been developed over the years. This study would discuss three of them: Trust in Physician Scale, Primary Care Assessment Survey, and Wake Forest Physician Trust Scale.

\section{Trust in Physician Scale}

The most widely used assessment measure is the Trust in Physician Scale (Anderson \& Dedrick, 1990). This scale was the first trust assessment measure designed specifically to assess the patient-physician relationship. An initial 25-item scale was generated based on patient interviews and other assessment measures, which eventually resulted in an 11-item, intervieweradministered measure. All items are on a 5-point Likert scale, with ratings from "1" (Strongly disagree) to "5" (Strongly agree). Higher scores reflect greater levels of trust. Reliability estimation using 160 male patients from the outpatient clinic in the Veterans Administration Medical Center in Fayetteville, North Carolina yielded a Cronbach's alpha coefficient of 0.90. Thom and colleagues conducted additional psychometric evaluations of the scale with a larger sample size $(n=414)$ from 20 community-based, primary care practices in Northern California (1999). Test-retest reliability was reported as 0.77 after one month and Cronbach's alpha was 0.89 (Thom et al., 1999). Construct validity was demonstrated, as trust was strongly correlated 
with satisfaction with care received by the patient's physician $(r=.73)$ and perceived humanness of physician behavior during the visit $(\mathrm{r}=.68)$ (Thom et al., 1999). Separate validity and reliability were not obtained for younger and older adults. The Trust in Physician scale has been criticized for its small initial examination sample size $(n=160)$ and for the fact that the participants were all male patients from the Fayetteville VA (Hall et al, 2002). The measures administered along with the Trust in Physician Scale to provide construct validity evidence (Multidimensional Health Locus of Control and an abbreviated 9-item version of the MarloweCrowne Social Desirability Scale) are also inadequate. They provide limited construct validity evidence due to the small number of scales administered and the nature of the constructs measured. The construct of trust is multifaceted and the variables associated with trust that help provide construct validity evidence are sundry, requiring measures of multiple conceptually related constructs to establish construct validity evidence (Cronbach \& Meehl, 1955). The authors of the Scale included only measures of the constructs of health and social desirability. While the Trust in Physician scale is the most widely used assessment measure of trust, the scale provides measures of unknown validity.

\section{Primary Care Assessment Survey}

The Primary Care Assessment Survey (Safran et al, 1998) (PCAS) is a 51-item, selfreport questionnaire, which consists of 11 subscales. The trust subscale consists of 8 items devised to assess the trust domains of agency, competence, and integrity. The scale was developed with a stratified sample of 7,204 adults employed by the Commonwealth of Massachusetts. All items are on a 5-point Likert scale, ranging from "Strongly disagree" to "Strongly agree." Each individual subscale was assessed for inter-scale correlations and score distribution characteristics. Reliability of each of the 11 subscales ranged from a Cronbach alpha 
of 0.74 to 0.95 (Safran et al, 1998). Test-retest reliability was not reported. Physician's competence, which is often considered an important aspect of patient-physician trust, is not assessed in the items in the Primary Care Assessment Survey (Hall et al., 2001). Additional measures were not administered along with the subscales in the survey. Evidence for construct validity was presented as correlations amongst the Survey subscales, which is insufficient. In their review of the Primary Care Assessment Survey, Haggerty and colleagues reported that participants found the trust subscale questions required too much guessing or were irrelevant (2011).

\section{Wake Forest Physician Trust Scale}

The Wake Forest Physician Trust Scale (WFPTS), sometimes known as the Interpersonal Trust in Physician Scale, was developed by Hall et al. (2002) to measure levels of patient trust in primary care providers. The authors' stated intent for the construction of this scale was to improve upon previously developed scales, specifically scales with an incomplete or limited scale development process and an inconsistent conceptualization of trust. This scale will be discussed in greater detail than the foregoing measures because it is arguably the best developed of the trust of physician scales and because it will be used to inform this study. The conceptual model of patient trust in their primary care providers, developed by the same authors, guided their item development and selection process. The model was established after a review of both the theoretical and empirical literature and focuses on five domains of trust including fidelity, competence, honesty, confidentiality, and global trust (Hall et al., 2001). The Wake Forest Physician Trust Scale consists of 10 items that employ a Likert-Type rating scale. The authors of the instrument originally generated 78 questions, which were created and/or modified during item development. Modifications of items were informed by an expert review panel, two focus 
groups, and pilot testing. The revised items were then field tested and revised through eight rounds of pilot study. Next, the resulting 26-items were tested in a national phone survey of 959 participants in the general population and in a regional (North Carolina) survey of 1,199 Health Maintenance Organization members. After factor analyses, redundant items, items with the lowest absolute loadings on the main factor of trust, and items with the lowest item-to-total correlations (below .70) were eliminated resulting in the final 10-item questionnaire.

Total scores on the WFPTS are obtained by summing the 10 item scores (reverse-scored for negative items), with a higher score indicating more trust. Three items are negatively worded while seven are positively worded. Internal consistency reliability was estimated by calculating a Cronbach's alpha of 0.93 and two-month test-retest reliability of 0.75 was estimated using the regional survey participants (Hall et al, 2002). The psychometric properties of the WFPTS in older adults have not yet been examined.

While there have been developments in current research on the psychosocial variables associated with patient-physician trust, there continues to be the need for a psychometrically sound measure of trust, as well as a further need for psychometric evaluation of already developed measures (Pearson \& Raeke, 2000; Hall et al., 2002; Muller et al., 2014). Having a measure of patient-physician trust with good psychometric properties would enable researchers to be confident in the meaning and reliability of the scores they obtain (Hall et al., 2002; Muller et al., 2014).

Although the WFPTS is the strongest measure of physician trust currently in use when assessing scale development, it is unknown how well this instrument performs with an older adult population. This is also no measure of patient-physician trust specific to older adults or even a measure that can be successfully generalized to an older adult population. As discussed 
above, it is important that the construct of trust of physicians is understood in an older adult population, as it may be distinct from how the construct is comprehended in a young adult population. There is a need for an instrument of trust that provides valid measures of physicianpatient trust in older adults. Using an instrument that was developed with young adults in research on older adult populations (among whom psychometric properties have not been established) can lead to invalid conclusions as measurement invariance cannot be assumed with different age groups.

\section{Current Study}

\section{Statement of the Problem}

Stronger patient trust of physicians is associated with higher rates of medical treatment adherence, greater continuity of care and, increased willingness to disclose sensitive information, higher likelihood of seeking treatment when treatment is needed, higher likelihood of following the recommendations put forth by the physicians, higher likelihood of granting the physicians' decisional authority, higher likelihood of returning for follow up care appointments, and increased patient satisfaction with care (Arora \& McHorney, 2000; Pearson \& Raeke, 2000; Hall et al., 2001; Thom et al., 2002; Salkend, 2004; Thom, Hall, \& Pawlson, 2004; Trachtenberg, Dugan, \& Hall, 2005; Berrios-Riveria et al., 2006; Julliard et al., 2008; Platonova, Kennedy, \& Shewchuk, 2008; Weng, 2008; Alrubaiee \& Alkaa'ida, 2011). These findings are encouraging, although their strength and validity is arguably tenuous in light of the questionable psychometric properties of the instruments used to obtain these results. A review of current measures of patient-physician trust revealed that there is insufficient validity evidence. In addition, there is limited evidence to support the validity and data obtained with currently available instruments when used with older adults. 
Upon consideration of the foregoing issues with the assessment of patient-physician trust with existing measures, the present study was designed to re-examine the psychometric properties of the Wake Forest Physician Trust Scale using more properly selected measures to obtain convergent and discriminant validity evidence. The WFPTS was selected for this study primarily because of its appropriate and comprehensive scale development process, notwithstanding problems with the gathering of validity evidence. The evidence in support of the validity of data obtained with the Wake Forest Physician Trust Scale is insufficient. While Hall and colleagues do have convergent validity evidence, the measures chosen to obtain this evidence were conceptually inadequate. Consequently, the obtained validity evidence is unconvincing. The measures administered along with the WFPTS to establish construct validity evidence included the 10-item Patient Trust Scale (Kao et al., 1998), the 11-item Health Insurer Trust Scale (Zheng et al., 2002), a single item on satisfaction "Overall, you are extremely satisfied with [your doctor]," and a 12-item Satisfaction Item scale on patient satisfaction (Hall et al., 1990). The Patient Trust Scale (Kao et al., 1998) was developed to measure patient-insurer trust and the relationship with physician payment method. Although research has established a relation between insurer trust and physician trust (Hall et al, 2002; Goold, Hessler, \& Moyer, 2006), items on the scale are specific to membership in managed care and insurer trust, which is a construct distinct from patient-physician trust. The authors of the Health Insurer Trust Scale (Zheng et al., 2002) developed the measure to assess patients' trust in health insurers and thus it suffers from the same issues as the Patient Trust Scale. The authors then asked five additional questions that were designed to obtain additional construct validity evidence for variables thought to be related to physician trust. The questions were: whether the participant had enough choice in selecting a physician (yes/no response choices); number of years with physician; 
willingness to recommend to friends (response choices ranged from Strongly Agree to Strongly Disagree); past disagreement or dispute with the physician (yes/no response choices); desire to switch physicians (response choices ranged from Strongly Agree to Strongly Disagree); and whether the participant belongs to a managed care plan (yes/no response choices). No reliability or validity evidence is reported for the five individual items. The inclusion of the 12 -item Satisfaction Item scale on patient satisfaction (Hall et al., 1990) was acceptable.

The authors of the Wake Forest Physician Trust Scale conducted an extensive scale development process and used both regional and national samples. Hall et al. also note that the development of the Wake Forest Physician Trust Scale was the first attempt to compare and reconcile differences among existing trust instruments (2002). Yet, the measures used to gather convergent validity evidence were poorly chosen in light of the theory upon which the Wake Forest Physician Trust Scale was developed, focusing on the five domains of trust including fidelity, competence, honesty, confidentiality, and global trust. Although the WFPTS is the "best" measure of physician trust, best because of its suitable and thorough scale development process, the construct validity evidence of the WFPTS is questionable and the scale has no validity or reliability evidence for older adults. How well this instrument performs with an older adult population is unknown, and the validity evidence for a young adult population is insufficient. The purpose of the present study is to examine the psychometric properties of the WFPTS in samples of young and older adults. Evidence for reliability and construct validity (convergent and discriminant evidence) was gathered.

\section{Research Aims and Hypotheses}

Aim 1: The first aim was to examine convergent validity evidence for the WFPTS. This was done separately for a young adult and an older adult sample. 
Hypothesis 1: The first hypothesis was that the strength of relations between scores on the WFPTS and measures of related constructs for the young adult participants would be moderate to strong, as expected based on previous research and the nomological network (Cronbach \& Meehl, 1995) for this study. These related constructs include patient's satisfaction, physician empathy, confidentiality, trustworthiness, health locus of control, and decisionmaking. The relations between the WFPTS scores and scores on these other measures was expected to provide convergent validity evidence for the young adult sample.

Hypothesis 2: The second hypothesis was that the strength of relations between scores on the WFPTS and measures of related constructs for the older adult participants would be moderate to strong, as expected based on previous research and the nomological network (Cronbach \& Meehl, 1995) for this study. These related constructs include patient's satisfaction, physician empathy, confidentiality, trustworthiness, health locus of control, and decisionmaking. The relations between the WFPTS scores and scores on these other measures were expected to provide convergent validity evidence for the older adult sample.

Aim 2: The second aim was to examine the discriminant validity evidence for the WFPTS with young adult and older adult samples.

Hypothesis 3: The third hypothesis was that the relations between scores on the WFPTS and measures of constructs for the young adult participants that were expected to be weakly related would be weakly related based on previous research and the nomological network (Cronbach \& Meehl, 1995) for this study. These weakly related constructs include general selfrated health and openness. The relations between scores on the WFPTS and scores on these other measures were expected to provide discriminant validity evidence for the young adult sample. 
Hypothesis 4: The fourth hypothesis was that the relations between scores on the WFPTS and measures of constructs for the older adult participants that were expected to be weakly related would be weakly related based on previous research and the nomological network (Cronbach \& Meehl, 1995) for this study. These weakly related constructs include general selfrated health and openness. The relations between scores on the WFPTS and scores on these other measures were expected to provide discriminant validity evidence for the older adult sample.

Aim 3: The third aim was to examine the reliability evidence for the WFPTS with a young adult and an older adult sample.

\section{Method}

\section{Participants and Sample Size}

Study participants were recruited through Amazon's Mechanical Turk (mTurk), an online marketplace for the coordination of workers to complete tasks. mTurk has been used in past research studies to collect questionnaire and survey data for behavioral research (Buhrmester, Kwang, \& Gosling, 2011; Mason \& Suri, 2012; Paolacci \& Chandler, 2014). Power analyses using G*Power 3.1.9 (Faul, Erdfelder, Buchner, \& Lang, 2013) were conducted to determine the sample size required for this study. The sample size for a two-tailed test of two independent Pearson r's was determined for an effect size of $f^{2}$ of $0.35, a=.05$, and power $=0.80$. The effect size used in the power analysis is based on previous studies evaluating patient-physician trust (Kelly et al, 2014). The power analysis indicated that a sample size of 264 participants was sufficient. The sample for this study consisted of 340 participants. A young adult group of participants between the ages of 18 and 64 was recruited and an older adult group of participants 65 years of age and older was recruited. Approximately an equal number of young and older 
adults were recruited. Participants must have been at least 18 years of age to participate.

Participants under 18 years of age were excluded from this study. Study participants were reimbursed $\$ 1.00$ for participating in this study.

\section{Measures}

Demographics Questionnaire. A demographic questionnaire was used to assess age, sex, ethnicity, highest education attained, marital status, occupational status, and year born. For a copy of the questionnaire, see Appendix A.

Wake Forest Trust in Physicians Scale (WFTPS). The WFPTS (Hall et al, 2002) was developed from a set of 26 items measuring patient trust in their physicians. Responses are on a Likert scale from "Strongly Agree" to "Strongly Disagree." Responses are summed, with total scores ranging from 10 to 50 . For a copy of all 10 items in the scale, refer to Appendix B. Reliability and validity information can be found in the introduction ("Wake Forest Physician Trust Scale (WFPTS)”. For this study, participants were also asked if they had a particular physician in mind when completing the WFPTS.

Philosophies of Human Nature: Trustworthiness Subscale (PHNT). The Philosophies of Human Nature Scale (Wrightsman, 1964) was developed as a scale to examine an individual's philosophies of human nature, which is envisioned as the expectancies that people have about the ways in which other people generally behave (Robinson, Shaver, Wrightsman, 1991). There are six subscales comprising the 84-item scale: trustworthiness, independence, altruism, strength of will and rationality, complexity of human nature, and variability of human nature. Only the trustworthiness subscale was used for this current study. The trustworthiness scale consists of 14 items, which use a 6-point Likert-type scale with response options ranging from (-3) disagree strongly to $(+3)$ agree strongly. Once the response options are summed, each subscale has a 
possible range of -42 (most negative) to +42 (most positive) for score per section. Initial examination included 530 undergraduate students at six universities across the United States. On the trust subscale, internal consistency was demonstrated by a split-half coefficient of 0.74 and a test-retest reliability coefficient after 3 months of 0.74 . Evidence for convergent validity is based on strong correlations between favorableness toward human nature and the Political Cynicism Scale ( $\mathrm{r}=-0.61$; Agger et al., 1961), Rosenberg's faith in people scale ( $\mathrm{r}=0.77$; Rosenberg, 1957) and Christie's Machiavellianism scale (r = -.068; Christie \& Geis, 1970; Robinson, Shaver, Wrightsman, 1991). For a copy of the scale, see Appendix C.

Jefferson Scale of Patient Perceptions of Physician Empathy (JSPPPE). The JSPPPE (Kane et al., 2007) was constructed as a brief instrument to measure physician empathy from the patient's perspective. The 5-item instrument uses a 7-point Likert-type scale with response options ranging from (1) Strongly Disagree to (7) Strongly Agree. Scores range from 5 to 35, with higher scores indicating higher patient perceptions of his or her physician's level of empathy. Initial reliability estimation using 252 medical patients resulted in a Cronbach's alpha coefficient of 0.58 (Kane et al., 2007). While the initial estimate was low, this could be because the scale only has five items and Cronbach's alpha coefficient is influenced by length of scale (Panayides, 2013; Agbo, 2014). Item-total score correlations ranged from 0.77 to 0.90 . Further examination by Hojat et al. (2010) of the reliability properties of the JSPPPE resulted in a Cronbach's alpha coefficient of 0.98. Evidence for convergent and discriminant validity is based on strong associations between patients' perceptions of their physicians' empathetic engagement and patient-physician trust $(\mathrm{r}=0.73-0.96)$, patient satisfaction $(\mathrm{r}=0.90-0.94)$ and patient compliance $(r=.80$; Kane et al., 2007; Hojat et al., 2010). For a copy of the scale, see Appendix D. 
Patient Satisfaction Scale (PSS). The Patient Satisfaction Scale (Hojat et al, 2011) is a 10-item scale developed to examine patients' satisfaction with their primary care physicians. The measure uses a 7-point, Likert-type response scale with response choices ranging from (1) "Strongly Disagree" to (7) "Strongly Agree." Participants are asked to respond to the items on the scale on the basis of their medical care from the preceding months. Participant ratings are summed with scores ranging from 10-70, with higher scores indicating greater satisfaction with physicians. Cronbach's coefficient alpha was 0.98 using a sample of 535 outpatients who completed a mailed survey through Thomas Jefferson University. Participants were included in this study if they were at least 18 years old and if they had at least two visits with their physician during the previous three years. Concurrent validity was established through correlations between the total scores of the satisfaction instrument and the total scores of the Jefferson Scale of Patient Perceptions of Physician Empathy $(r=0.69-0.96)$. For a copy of the scale, see Appendix E.

Autonomy Preference Index (API). The API (Ende et al., 1989) consists of two scales, a 15-item subscale designed to assess patients' preference for decision-making in medical settings and an 8-item subscale for measurement of information seeking preference. Factor analysis supported the clustering of decision making on one scale and information seeking preferences on the other. The 15-item subscale on decision-making was used for this study. The Index is a measure of patients' desire to make informed medical decisions, their desire to be kept abreast during the decision-making process, and who they believe should participate in their decision making process. The Index consists of six general items for decision-making followed by three clinical vignettes, each then is followed with three follow-up items. Participants' respond to each general item on a 5-point Likert scale, with response choices ranging from (1) 
strongly disagrees to (5) strongly agree. The three clinical vignettes represent different levels of illness severity; upper respiratory tract illness represents mild disease, high blood pressure represents moderate disease; and myocardial infraction represents severe or most threatening disease. Using the vignettes, participants are queried to hypothetically consider their participation preference for different stages of disease severity. In this section, response choices are: "you alone," "mostly you," "the doctor and you," "mostly the doctor," and "the doctor alone," to the question "Who should make the following decision?" Scores range from 0-100, with lower scores corresponding to low preference for decision-making and higher scores corresponding to high preference for decision-making. Initial reliability estimation using 312 medical patients yielded a Cronbach's alpha coefficient of 0.92 and test-retest reliability after two weeks of 0.84 . Factor analysis supported clustering of items into information $(\alpha=0.82)$ and participation subscales $(\alpha=0.82)$, and construct validity was assessed with the participation subscale and a global item on satisfaction $(r=0.54$; Ende et al., 1989). Reliability estimation with a sample of 190 chronic pain patients (mean age $=57$ ) resulted in a Cronbach's alpha of 0.61 (Spies et al., 2006). Estimation of internal consistency reliability in a sample of 110 women with pelvic floor disorders (mean age $=62$ ), revealed a Cronbach's alpha $=0.80$ and good testretest reliability (ICC=0.7; Sung et al., 2010). For a copy of the scale, see Appendix F.

\section{Multidimensional Health Locus of Control Scale Form A (MHLC). The MHLC}

(Wallston, Wallston, \& DeVellis, 1978) is an 18-item measure developed to assess a person's control beliefs related to his or her health. The MHLC consist of three, six-item subscales related to internal health locus of control (IHLC), changing health locus of control (CHLC), and external beliefs about "powerful others" (e.g. physician, health professionals; PHLC). The MHLC scales consist of two parallel forms; for this study Form A was used. The six-point 
Likert scale response options ranges from (1) strongly disagree to (6) strongly agree. Initial examination of 282 young adults in a Nashville, TN, airport demonstrated internal consistency estimates (Cronbach's alpha coefficients) ranging from $0.55-0.83$ for the subscales. Test-retest over a four to six month period ranged from $0.66-0.73$ for the subscales. Concurrent validity evidence is based on association with Levenson's Multidimensional Locus of Control Scale (1978), after which the MHLC was modeled. The Internal Health Locus of Control subset of the MHLC correlated with Levenson's Internality subscale $(r=0.57)$ and with the Chance subscale $(\mathrm{r}=0.80)$ (Wallston, Wallston, \& DeVellis, 1978; Robinson, Shaver, Wrightsman, 1991). The Internal Health Locus of Control subset of the MHLC was also correlated with a two-item measure of self-reported health $(\mathrm{r}=0.40)$, and the Chance subscale of the MHLC was negatively correlated with the same two-item measure $(r=-0.28$; Wallston, 2005). In a sample of 152 medical and dental students (Winefield, 1982), the MHLC demonstrated internal consistency ranging from 0.49-0.70. For the full MHLC, see Appendix G.

Confidentiality. A single Likert item was administered to assess confidentiality. The question, "To what extent do you think your physician will keep your information private?" will help examine the importance of confidentiality for a patient's trust in his or her physician. Response options will range from (1) strongly disagree to (5) strongly agree.

Self-Rated Health. A single Likert item was administered to assess self-rated health. The question, "How would you rate your health at the present time: Excellent, good, fair, or poor?" will examine the role self-rated health has on patient's trust in his or her physician. Selfassessed health is one of the most frequently utilized indexes of well-being (Jylhä, 2009), and it is this single-item measure that is often administered (Graf \& Patrick, 2016; Zajacova \& Dowd, 2011). This item was adapted from the 36-item Medical Outcome Study Short Form (SF-36) 
(Ware \& Sherbourne, 1992). In a sample of 21,732 participants in the Veterans Affairs Ambulatory Care Quality Improvement Project (DeSalvo et al., 2005), the item demonstrated predictive validity for identifying participants at risk of death within the year subsequent to baseline measurement with an area under curve (AUC) of 0.74 , VA Admissions within the year with an AUC of 0.63 , and high utilization of outpatient services within the year with an AUC of 0.61 .

Self-Rated Mental Health. A single Likert item was administered to assess self-rated mental health (SRMH). The question, "How would you rate your mental health at the present time: Excellent, good, fair, or poor?" was intended to examine the role self-rated mental health has on patient's trust in his or her physician. Single-item measures of SRMH are becoming increasingly common to help reduce respondent burden and assist in simplifying assessment administration (Ahmad et al., 2014). In a sample of 420 older adults, self-rated mental health was significantly correlated with other measures of mental health, specifically the PHQ-9 (r = 0.50), CES-D ( $\mathrm{r}=0.42)$, and GDS-SF $(\mathrm{r}=0.42)$ (Jang et al., 2012). In a sample of 237 adults from the Epidemiological Catchment Area study conducted in New Haven, CT, when controlling for gender, age, and past history of depression, participants with self-reported poor mental health were 4.57 times more likely to experience a major depressive episode than those individuals with fair mental health and 9.97 times more likely than those who rated themselves as having excellent self-rated mental health (Hoff et al., 1997).

Personality Traits. The Mini-International Personality Item Pool (Mini-IPIP; Donnellan, Oswald, Baird, \& Lucas, 2006) is a five factor, 20-item measure of personality derived from the 50-item International Personality Item Pool (Goldberg, 1999). Factors include: Openness to Experiences (Intellect/Imagination), Conscientiousness, Extraversion, Agreeableness, and 
Neuroticism. The five-point Likert scale included response choices ranged from (1) strongly agree to (5) strongly disagree. Initial examination of 2,992 undergraduate participants demonstrated internal consistency estimates for the five factors ranging from $0.65-0.82$ for the subscales (Donnellan, Oswald, Baird, \& Lucas, 2006). Test-retest reliability coefficients over a three-week period ranged from $0.62-0.87$ for the subscales and test-retest reliability coefficients over a nine-month period ranged from $0.68-0.86$ for the subscales. Concurrent validity evidence for the Mini-IPIP was demonstrated using the Big Five Inventory (John \& Srivastava, 1999). Correlation coefficients for the relations between the Mini-IPIP subscales and Big Five Inventory subscales ranged from 0.49-0.81 (Donnellan, Oswald, Baird, \& Lucas, 2006). In a sample of 15,701 young adults in the National Longitudinal Study of Adolescent Health (Baldasaro, Shanahan, \& Bauer, 2013), the Mini-IPIP demonstrated internal consistency with coefficients ranging from $0.68-0.78$ for the subscales, and each of the personality scales were significantly correlated with perceived stress, hostility, and mastery. In a sample of 8,183 online participants, Evans \& Revelle (2008) found that trust, as measured by the Propensity to Trust Scale, was correlated with the Big Five traits specifically agreeableness $(r=0.27)$, extraversion $(r=0.66)$ and neuroticism $(\mathrm{r}=-0.57)$. There was a small correlation between consciousness and trust $(\mathrm{r}=$ 0.16). The correlation between trust and the Openness to Experience subscale was $r=0.0$. Openness seems to be the only subscale that is not at least somewhat related to trust, which is why it was used to provide discriminant validity evidence. In this study, high openness scores are coded to indicate lower self-ratings of openness on the Mini-IPIP. For a copy of the scale, see Appendix G. 


\section{Procedures}

When participants chose to complete the survey online, they were presented first with a cover letter discussing the study, description of the procedures, discomforts, benefits, financial considerations, confidentiality, and informed consent. Then they were asked their birth year as an element of the validity checks, which was used to screen for individuals in the two age groups. Participants then completed the questionnaires. At the end of the survey, participants were asked for their age in years. The order of the questionnaires was randomized in mTurk when administered to participants.

To increase the likelihood of including individuals who provided high quality data, a validity check was included to detect any invalid data due to misrepresentation of age. Individuals were asked their birth year at the beginning of the survey and then their corresponding age in years at the end of the survey. During data cleaning, discrepancies between responses to these items resulted in exclusion of 107 participants from the final samples. Participants were excluded in Sample 1 and Sample 2 for non-matching age at the start and end of the survey, non-matching year born at the start and end of the survey, non-matching age in years and year they reported being born, and for one response option on items that were reversescored on scales. Participants were also removed for inconsistent responding, specifically choosing one response option for all items on a scale that included reverse-scored items.

Sample 1. For the young adult group, 210 individuals began the survey online. Participants who did not include their age or who were not between the ages of 18-64 were excluded from the study, leaving 188 participants. Additional participants were excluded from the study based on the validity test noted above, resulting in a final sample of 179 participants. 
No variables in the data set exhibited more than 5\% missingness. A Little's Misssing Completely At Random test (Little, 1986) was conducted to determine if the missingness in the data gathered was missing completely at random, missing not at random, or missing at random. The test was not significant $(\mathrm{p}=.922)$, therefore the data were considered to be missing completely at random.

Sample 2. For the older adult group, 237 individuals started the study but with participants excluded, 169 participants remained. Additional participants were excluded from the study based on the validity test noted above, resulting in a final sample of 161 participants.

No variables in the data set exhibited more than 5\% missingness. A Little's Missing Completely At Random test (Little, 1986) was conducted for the same purpose as for Sample 1. The test was not significant $(p=.469)$, therefore the data were considered to be missing completely at random.

The West Virginia University Institutional Review Board approved the collection of data in young and older adults.

\section{Results}

\section{Participant Sample Characteristics}

The ages of participants in Sample 1 ranged from 18 to 64 years, and the age of participants in Sample 2 ranged from 65 to 87 years. Both samples were comprised of a majority of White/Caucasian, not Hispanic participants, each with the same number of male and female participants. The samples collected were diverse with regard to race, which is reflective of the diversity of participants utilizing mTurk in the U.S. (Buhrmester, Kwang, \& Gosling, 2011). The education levels for both samples were relatively high, with the majority of Sample 1 and Sample 2 participants having a college degree. Use of Chi-square tests indicated that there were 
no statistically significant differences $(\alpha<.05)$ between the two samples with regard to demographic variables. For complete information on age, gender, race/ethnicity, and level of education per sample, see Table 1.

Mean scores on each assessment measure for Sample 1 can be found in Table 2, and means for Sample 2 can be found in Table 3. Younger adults had lower scores on patientphysician trust, patient perception of physician empathy, openness, and external beliefs about "powerful others," and higher scores on decision-making autonomy than older adults.

On the WFPTS scale, the reported mean score was $40.8(\mathrm{SD}=6.2)$ for the national sample of 959 participants (Hall, Dugan, Zheng, \& Mishra, 2001). Mean scores for the WFPTS in this current study was $35.9(\mathrm{SD}=6.12)$ for young adult participants and $36.1(\mathrm{SD}=6.11)$ for older adult participants.

\section{Data Management}

Descriptive statistics (mean, standard deviation) were first computed to describe the sample, and mean distributions of the variables were plotted for each dependent variable. Total scores on all scales missing less than $20 \%$ of items and three items or less were prorated by summing the completed items, dividing the sum by the number of completed items, and then multiplying that by the number of items on the scale. There was less than $2 \%$ of missing data using this method.

Assumptions that needed to be met for Pearson's correlation analyses were tested during analyses. One assumption is that dependent variables must be interval or ratio, which was the case in this study. For the present study, outliers were defined as scores greater or less than 3.2 standard deviations from the mean (Tabachnick \& Fidell, 2012). The presence of outliers was tested and the box plot and histograms of the variables were also examined, resulting in 17 
outliers being excluded from the study. Linearity was examined through the use of scatterplots. The assumption of normality was assessed by analyzing the skewness and kurtosis of the variables and through the use of histograms. After the removal of outliers in the data, the question measuring confidentiality had high kurtosis but was not skewed. A log transformation was completed, yet this caused the measure to be more positively skewed than initially. Therefore, lack of skew was prioritized over kurtosis and the original value of the variable was maintained.

\section{Results for Aim 1: Construct Validity Evidence.}

Aim 1: The first aim was to examine convergent validity evidence for the WFPTS. This was done separately for a young adult and an older adult sample.

To test Hypothesis 1, that the strength of relations between scores on the WFPTS and measures of related constructs will be moderate to strong for the young adult sample and have statistically significant relations, as expected based on previous research and the nomological network (Cronbach \& Meehl, 1995) for this study, Pearson product moment correlation analyses were conducted. Relations of the WFTPS and measures of patient-physician trust, patient's satisfaction, physician empathy, confidentiality, trustworthiness, health locus of control, and decision-making, and each of the other scales for young adults were examined. The correlation matrix can be seen for this hypothesis in Table 2. As hypothesized, scores on the WFPTS and the following related constructs for adults were moderate to strongly correlated with scores on the measures of trustworthiness, physician empathy, patient's satisfaction, decision-making autonomy, and confidentiality. The relation between the WFPTS and health locus of control were relatively weak. 
To test Hypothesis 2, that the strength of relations between scores on the WFPTS and measures of related constructs will be moderate to strong for the older adult sample and have statistically significant relations, as expected based on previous research and the nomological network (Cronbach \& Meehl, 1995) for this study, Pearson product moment correlation analyses were conducted. Relations of the WFTPS and measures of patient-physician trust, patient's satisfaction, physician empathy, confidentiality, trustworthiness, health locus of control, and decision-making, and each of the other scales for older adults were examined using correlation analyses. The correlation matrix can be seen for this hypothesis in Table 3. As hypothesized, scores on the WFPTS and the following related constructs for older adults were moderate to strongly correlated with scores on the measures of trustworthiness, physician empathy, patient's satisfaction, decision-making autonomy, and confidentiality. The relation between the WFPTS and health locus of control were relatively weak.

\section{Results for Aim 2: Discriminant Validity Evidence}

Aim 2: The second aim was to examine the discriminant validity evidence for the WFPTS with young adult and older adult samples.

To test Hypothesis 3, that the relations between scores on the WFPTS and measures of constructs that were expected to be weakly related would be weakly related based on previous research and the nomological network (Cronbach \& Meehl, 1995) for the young adult sample in this study, Pearson product moment correlation analyses were conducted. Relations of the WFTPS and measures of general self-rated health and openness, and each of the other scales for adults were examined using correlation analyses. The correlation matrix can be seen for this hypothesis in Table 2. As hypothesized, scores on the WFPTS for young adults were weakly correlated with the measures of openness and self-rated health. 
To test Hypothesis 4, that the relations between scores on the WFPTS and measures of constructs that were expected to be weakly related would be weakly related based on previous research and the nomological network (Cronbach \& Meehl, 1995) for the older adult sample in this study, Pearson product moment correlation analyses were conducted. Relations of the WFTPS and measures of general self-rated health and personality traits specifically openness, and each of the other scales for older adults were examined using correlation analyses. The correlation matrix can be seen for this hypothesis in Table 2. As hypothesized, scores on the WFPTS for older adults were weakly correlated with the measures of openness and self-rated health.

\section{Results for Aim 3: Reliability.}

Aim 3: The third aim was to examine the reliability evidence for the WFPTS with a young adult and an older adult sample.

To examine the reliability of the WFPTS scores, Cronbach's alpha and average inter-item correlation coefficients (Clark \& Watson, 1995) were calculated as indices of internal consistency for each of the two age groups. For Cronbach's alpha, estimates over 0.7 (Cortina, 1993; Nunnaly, 1978) are recommended and for average inter-item correlation, coefficients between 0.15-0.50 are recommended (Clark \& Watson, 1995). Reliability coefficients can be seen in Table 4.

\section{Discussion}

The purpose of this current study was to examine the psychometric properties of the Wake Forest Physician Trust Scale with samples of young adults and older adults. Previously reported psychometric evidence was based on less properly selected measures for establishing convergent validity evidence, and was limited to a young adult sample. The present examination 
of the convergent and discriminant validity evidence for the Wake Forest Physician Trust Scale provides support for the validity of scores obtained as a measure of patient-physician trust for young and older adults. Support for the reliability of the scores obtained with the Wake Forest Physician Trust Scale was also found with both age groups.

\section{Young Adult Sample}

Hypothesis 1, regarding convergent validity, was mostly supported by the results of the current study. The Wake Forest Physician Trust Scale with young adult participants demonstrated good convergent validity via significant, strong correlations with the Jefferson Scale of Patient Perceptions of Physician Empathy and Patient Satisfaction Scale and significant, moderate correlations with the Philosophies of Human Nature: Trustworthiness Subscale, Autonomy Preference Index, and Confidentiality scales. The Internal Health Locus of Control and External Beliefs about "Powerful Others" subscales of the Multidimensional Health Locus of Control scale demonstrated statistically significant, but relatively weak effect sizes relative to the other effect sizes for the other measures as expected on the basis of the proposed nomological network. This pattern of relations was mostly expected based on the literature relating trust to several of these variables. For example, the strong correlation between the Wake Forest Physician Trust Scale and the Patient Satisfaction Scale is consistent with what was expected based upon the previously discussed relation between patient-physician trust and patient satisfaction (e.g. Thom et al., 2002; Safran et al., 1998; Platonova, Kennedy, \& Shewchuk, 2008; Weng, 2008). Literature of how patients' perception of the empathy levels of their physicians is still developing; yet the relation between patient-physician trust and empathy has been established (e.g. Hojat, 2007; Hojat et al., 2009). The relation between patient-physician trust and decision-making across ages was moderate and statistically significant, which is also 
supported in the literature (e.g. Trachtenberg, Dugan, \& Hall, 2005; Kraetschmer et al., 2004). The Multidimensional Health Locus of Control scale demonstrated a relatively weak effect size even though the relation between the Wake Forest Physician Trust Scale and the Multidimensional Health Locus of Control Scale was statistically significant. The limited convergent evidence provided was unexpected. Based on the anticipated hypothesis, it was assumed the relation would be moderate to strong, however this turned out not to be the case. It was thought that patient-physician trust would relate to the extent which a person felt in control of their health in relation to chance and belief in "powerful others," like a physician, although this was not true in the current study.

Hypothesis 2, regarding discriminant validity, was supported. A small and nonsignificant correlation was found between the Wake Forest Physician Trust Scale and the MiniInternational Personality Item Pool Openness subscale. A small and significant correlation was demonstrated between the Wake Forest Physician Trust Scale and Health scale. This result provides discriminant validity evidence, albeit more limited support than that of the Openness subscale. As expected, the relation between patient-physician trust and openness is quite weak based on the existing literature (Evans \& Revelle, 2008) and supported in this current study. Within this study the relation between the health scale and the Wake Forest Physician Trust Scale is also weak, which was true for a study that examined the psychometric properties of the Dutch adaption of the Wake Forest Physician Trust Scale as well and reached the same conclusion (Bachinger, Kolk, \& Smets, 2009), providing further discriminant validity evidence. Reliability coefficients reveal satisfactory internal consistency reliability, as Cronbach's alpha and average inter-item correlations for the young adult sample were both above the recommended coefficient parameters for reliability. 


\section{Older Adult Sample}

Hypothesis 3 was mainly supported by the results of the current study. The correlations between the Wake Forest Physician Trust Scale and other measures in the older adult sample provide support for the construct validity of the measures obtained with the Wake Forest Physician Trust Scale in older adults. Like the young adult participants, the Wake Forest Physician Trust Scale demonstrated good convergent validity via significant, strong correlations with the Jefferson Scale of Patient Perceptions of Physician Empathy and Patient Satisfaction Scale and significant, moderate correlations with the Philosophies of Human Nature:

Trustworthiness Subscale, Autonomy Preference Index, and Confidentiality scales. These significant, moderate to strong correlations provided convergent validity evidence for the Wake Forest Physician Trust Scale with an older adult population. As with the young adult sample, the expected patterns of relations between the Wake Forest Physician Trust scale and the related variables were obtained for convergent validity evidence (e.g. Hojat et al., 2009; Platonova, Kennedy, \& Shewchuk, 2008; Weng, 2008; Hojat, 2007; Trachtenberg, Dugan, \& Hall, 2005; Kraetschmer et al., 2004; Thom et al., 2002; Safran et al., 1998). The Internal Health Locus of Control and External Beliefs about "Powerful Others" subscales of the Multidimensional Health Locus of Control scale provided relatively weak convergent validity as compared to that found with the other measures used to obtain convergent validity evidence. This was hypothesized to be for similar reasons discussed with young adults.

Hypothesis 4, regarding discriminant validity, was also supported. The relations between Wake Forest Physician Trust Scale and the Mini- International Personality Item Pool Openness subscale and Health scale were small and for the Openness subscale, non-significant. As with young adults, the relation between patient-physician trust and openness, and patient-physician 
trust and self-rated health, were weak based on the existing literature (e.g. Evans \& Revelle, 2008; Bachinger, Kolk, \& Smets, 2009) and supported in this current study.

The reliability coefficients for the older adult sample confirmed the measure's internal consistency, since Cronbach's alpha and average inter-item correlations for the older adults sample were each above the recommended coefficient parameters for reliability.

In summary, the principal goal of the present study was to examine the psychometric properties of the Wake Forest Physician Trust Scale using more properly selected measures to obtain construct validity evidence. A secondary goal was to provide a psychometric examination of the Scale with an older adult. The present results support the psychometric properties of the Wake Forest Physician Trust Scale with both young adults and older adults, which will hopefully enhance the confidence with which researchers can use this instrument. In addition, the results obtained with older adults open the door for future research on physician trust among the older adult populations. The lack of a physician trust measure that is suitable for older adults may have hindered research on older adult trust of physicians, or at least led researchers to question the validity of findings with unsupported measures. Since measurement invariance in patientphysician trust across the lifespan cannot be assumed, separate scales with strong psychometric properties for different age groups are a good first step. Older adults are the most frequent users of healthcare (Dugan, Trachtenberg, \& Hall, 2005) and with increased longevity and a growing number of older adults in our society, there is an increasing need to understand physician trust of older adults and the factors that contribute to or diminish this trust.

\section{Limitations}

There are a few limitations of this study. One potential limitation is the use of Amazon's mTurk for data collection, as there may be concerns about a lack of diversity amongst recruited 
participants. Many of the participants were well educated with access and capability to complete an hour survey on a computer. Also, the mean age of the older adult sample was 68 years. Therefore, the sample consisted of rather "young" older adults, raising questions of whether mTurk is a suitable method for recruiting late-life adult participants. However, sample participants recruited from mTurk are often more demographically diverse than either college samples or standard Internet samples, and data collected from mTurk is at least as reliable as that obtained by traditional data collection methods (Buhrmester, Kwang, \& Gosling, 2011). Agegroup comparisons of data recruited with older adults using mTurk are also comparable to findings from community samples, supporting that mTurk is a viable data collection option with older adult participants (Lemaster, Pichayayothin, \& Strough, 2015).

An additional potential limitation involves the use of reverse-coded items within the measures administered. For older adults switching from positively worded to negatively worded questions and back again can make comprehension of the questions challenging (Mohlman et al., 2011). Reverse-coded items act like cognitive hurdles, which require respondents to engage in more controlled cognitive processing instead of more automatic processing (Podsakoff et al., 2003). Due to the increased cognitive demands required for reverse-coded items, older adult respondents may be more vulnerable to response biases and likely to use heuristics to reduce the cognitive load when completing assessments that use negatively worded questions. Nonetheless, reverse-coded items are necessary to determine if participants are paying attention to their responses and to reduce the chance of acquiescence bias occurring.

Finally, the use of self-report measures is always challenging within psychological research as it involves reliance on study participants to report honestly, reliably, and possess enough insight when completing the questionnaires administered to answer accurately. 
However, the best method for determining an individual's level of trust is to ask them about their trust. Trust in one's physician is not something that can easily be observed, therefore self-report measures are the method of choice for this type of assessment.

\section{Future Directions}

There are number of directions for future research that are enabled by the results of the present study. The availability of such a scale may enable researchers to explore the relations between trust and healthcare utilization, with a goal of enhancing healthcare utilization, particularly among individuals whose trust of physicians is less than optimal. Trust is an important factor in healthcare utilization (van den Berk-Clark \& McGuire, 2014). Treatment adherence, continuity, and belief in physician confidentiality are predicated on such trust when using healthcare services (van den Berk-Clark \& McGuire, 2014). Additionally, distrust in health-care settings and medical providers decreases healthcare utilization (LaVeist, Isaac, and Williams, 2000; O’Malley et al., 2004). Future research focused of individuals with high levels of physician trust can potentially augment healthcare utilization by determining successful ways to engender trust between patient and physician. These might include finding ways to improve patient satisfaction, increasing patients' perception of their doctor's empathy, and increasing public social trust in the specific medical institution.

Shared decision making between patient and physician, which has been strongly advocated in recent years, could also be explored in the context of physician trust. Trust is one of many potential important variables that come into play in the context of shared decision making between patient and physician.

The exploration of age differences in patient-physician trust is another avenue for future research. One could, for example, determine whether age-related differences exist in how 
individuals perceive trust. If differences are found, they could inform attempts to increase healthcare utilization, which is poorer among older adults than among young adults (e.g. Farrow, 2010; Nicholas \& Hall, 2012). Lower trust in physicians is associated with underutilization of healthcare services (Guerrero et al., 2015), however, older adults report higher levels of patientphysician trust than young adults (e.g. Boyd et al, 2008; Mainous et al., 2001; Simon, Zang, \& Dong, 2014). While older adults are more trusting as a group, there are still older adults who are less trusting. Therefore, examination of the relation between physician trust and healthcare utilization would be an interesting avenue for future research. Increased knowledge of age differences in trust may also allow physicians to have a stronger influence on the adherence of patients to medication regimens and follow up appointments depending on the patient's level of trust.

Finally, the exploration of potential differences in responses to the trust items in more specialized populations (those experiencing chronic health problems, terminal illnesses) would be interesting and potentially of heuristic value, as these individuals are more likely to be reliant on their physicians for information and shared decision making. 


\section{References}

Agger, R.E., Goldstein, M.N., \& Pearl, S.A. (1961). Political Cynicism: Measurement and meaning. The Journal of Politics, 23(3): 477-506.

Ahmad, F., Jhajj, A.K., Stewart, D. E., Burghardt, M., \& Bierman, A.S. (2014). Single item measures of self-rated mental health: a scoping review. BMC Health Services Research, 14(398), 1-11. doi: 10.1186/1472-6963-14-398.

Alrubaiee, L. \& Alkaa'ida, F. (2011). The mediating effect of patient satisfaction in the patients' perception of healthcare quality- patient trust relationship. International Journal of Marketing Studies, 3(1), 103- 127. doi: 10.5539/ijms.v3n1p103

Anderson, G. F. (2010). Chronic care: making the case for ongoing care. Robert Wood Johnson Foundation.

Anderson, L.A. \& Dedrick, R.F. (1990). Development of the Trust in Physician Scale: A measure to assess interpersonal trust in patient-physician relationships. Psychological Reports, 67(3 Pt 2), 1091-100. doi: 10.2466/pr0.1990.67.3f.1091

Arora, N.K., \& McHorney, C.A. (2000) Patient preferences for medical decision making: who really wants to participate? Medical Care, 38(3), 335-341.

Bachinger, S.M., Kolk, A.M., \& Smets, EM.A. (2009). Patients' trust in their physician:

Psychometric properties of the Dutch version of the "Wake Forest Physician Trust Scale." Patient Education and Counseling, 76, 126-131.

Baldasaro, R. E., Shanahan, M. J., \& Bauer, D. J. (2013). Psychometric Properties of the MiniIPIP in a Large, Nationally Representative Sample of Young Adults. Journal of Personality Assessment, 95(1), 74-84. doi: 10.1080/00223891.2012.700466

Bell, R.A., Arcury, T.A., Ip, E., Grzywacz, J.G., Ngyuen, H., Kirk, J.K.,....Quandt, S.A. (2013). 
Correlates of physician trust among rural older adults with diabetes. American Journal of Health Behavior, 37(5), 660-666. doi: 10.5993/AJHB.37.5.10

Berrios-Riveria, J.P., Street, R.L., Garcia Popa-Lisseanu, M.G., Kallen, M.A., Richardson, M.N., Janssen, N.M., .....Suarez-Almazor, M.E. (2006). Trust in physicians and elements of the medical interaction in patients with rheumatoid arthritis and systemic lupus erythematosus. Arthritis \& Rheumatology, 55(3), 385-393. doi: 10.1002/art.21988

Brincks, A.M., Feaster, D.J., Burns, M.J., \& Mitrani, V.B. (2010). The influence of health locus of control on the patient-provider relationship. Psychology, Health \& Medicine, 15(6), 720-728. doi: 10.1080/13548506.2010.498921

Buhrmester, M., Kwang, T., \& Gosling, S.D. (2011). Amazon’s Mechanical Turk: A new source of inexpensive, yet high-quality, data? Perspectives on Psychological Science, 6, 3-5. doi: $10.1177 / 1745691610393980$

Caterinicchio, R.P. (1979). Testing plausible path models of interpersonal trust in patientphysician relationships. Social Science \& Medicine. Part A: Medical Psychology \& Medical Sociology. 13A(1), 81-99.

Christie, R. \& Geis, F. (1970). Machiavellianism scale. Studies in Machiavellianism. NY, NY: Academic Press.

Clark, L., \& Watson, D. (1995). Constructing validity: Basic issues in objective scale development. Psychological Assessment, 7(3), 309-319.

Cortina, J.M. (1993). What is coefficient alpha? An examination of theory and applications. Journal of Applied Psychology, 78(1), 98-104.

Cronbach, L. and Meehl, P. (1955). Construct validity in psychological tests, Psychological Bulletin, 52, 4, 281-302. 
Davis, H.T. \& Rundall, T.G. (2000). Managing Patient Trust in Managed Care. The Milbank Quarterly, 78(4), 609-924. doi: 10.1111/1468-0009.00187

DeSalvo, K.B., Fan, V.S., McDonnell, M.B., \& Fihn, S.D. (2005). Predicting mortailty and healthcare utilization with a single-question. Health Services Research, 40(4), $1234-$ 1246. doi: 10.1111/j.1475-6773.2005.00404.x

Donnellean, M.B. \& Lucas, 2R.E. (2008). Age differences in the big five across the life span Evidence from two national samples. Psychology and Aging, 23(3), 558-566. doi: $10.1037 / \mathrm{a} 0012897$

Donnellan, M. B., Oswald, F. L., Baird, B. M., \& Lucas, R. E. (2006). The mini-IPIP scales: tiny-yet-effective measures of the Big Five factors of personality. Psychological Assessment, 18(2), 192-203. http://doi.org/10.1037/1040-3590.18.2.192

Elwyn, G., O’Connor, A., Stacey, D., Volk, R., Edwards, A., Coulter, A., ... Collaboration, I. P D. A. S. (IPDAS). (2006). Developing a quality criteria framework for patient decision aids: online international Delphi consensus process. BMJ, 333(7565), 417. doi: 10.1136/bmj.38926.629329.AE

Emanuel, E.J. \& Dubler, N.N. (1995). Preserving the physician-patient relationship in the era of managed care. The Journal of the America Medical Association. 273(4), 323-329.

Ende, J., Kazis, L., Ash, A. \& Moskowitz, M. (1989). Measuring patients' desire for autonomy: Decision making and information-seeking preferences among medical patients. Journal of General Internal Medicine, 4(1), 23-30.

Epstein, A.M., Lee, T.H., \& Hamel, M.B. (2004). Paying physicians for high-quality care. The New England Journal of Medicine, 350, 406-410. doi: 10.1056/NEJMsb035374

Evans \& Revelle (2008). Survey and behavioral measurements of interpersonal trust. Journal of 
Research in Personality, 42(6), 1585-1593. doi: 10.1016/j.jrp.2008.07.011

Farrow F. (2010). Overutilization and underutilization of preventive services in elderly populations, A conundrum. Marquette Elder's Advisor, 12(1), 103-122.

Faul, F., Erdfelder, E., Buchner, A., \& Lang, A.G. (2013). G*Power Version 3.1.7 [computer software]. Uiversität Kiel, Germany. Retrieved from: http://www.softpedia.com/get/Science-CAD/G-Power.shtml

Freburger, J.K., Callahan, L.F., Currey, S.S. \& Anderson, L.A. (2003). Use of the Trust in Physician Scale in patients with rheumatic disease: psychometric properties and correlates of trust in the rheumatologist. Arthritis \& Rheumatology, 49(1), 51-58. doi: 10.1002/art.10925

Goldberg, L. R. (1999). The IPIP-NEO (International Personality Item Pool Representation of the NEO PI-R $\left.{ }^{\mathrm{TM}}\right)$. Personality Psychology in Europe, 7, 7-28.

Goold, S.D., Fessler, D., \& Moyer, C.A. (2006). A measure of trust in insurers. Health Services Research Journal, 41, 58-78. doi: 10.1111/j.1475-6773.2005.00456.x

Goold, S.D. \& Lipkin, M. (1999). The doctor-patient relationship: Challenges, opportunities, and strategies. Journal of General Internal Medicine, 14(1), 26-33. doi: 10.1046/j.1525-1497.1999.00267.x

Graf, A. \& Patrick, J. (2016). Self-Assessed health into late adulthood: Insights from a lifespan perspective. GeroPsych, 29(4), 177-187. doi: 10.1024/1662-9647/a000156

Gruhn, D., Rebucal, K., Diehl, M., Lumley, M., \& Labouvie-Vief, G. (2008). Empathy across the adult lifespan: Longitudinal and experience-sampling findings. Emotion, 8(6), 753765. doi: $10.1037 / \mathrm{a} 0014123$

Guerrero, N., Mendes de Leon, C.F., Evans, D.A., \& Jacobs, E.A. (2015). Determinants of trust 
in health care in an older populations. Journal of American Geriatric Society, 63(3), 553557. doi: $10.1111 /$ jgs.13316

Haggerty, J.L., Beaulieu, C., Lawson, B., Santor, D.A., Fournier, M., \& Burge, F. (2011). What patients tell us about primary healthcare evaluation instruments: Response format, bad questions, and missing pieces. Health Policy, 7, 66-78.

Hall, M.A., Dugan, E., Zheng, B.Y., \& Mishra, A.K. (2001). Trust in physicians and medical institutions: What is it, can it be measured, and does it matter? Milbank Quarterly. 79, 613-639. doi: 10.1111/1468-0009.00223

Hall, M.A., Zheng, B.Y., Dugan, E., Camacho, F., Kidd, K.E., Mishra, A., \& Balkrishnan, R. (2002). Measuring patients' trust in their primary care providers. Medical Care Research and Review. 59, 293-318. doi: 10.1177/1077558702059003004

Hall, J.A., Feinstein, M., Fretwell, M.D., Rowe, J.W., \& Epstein, A.W. (1990). Older patients' health status and satisfaction with medical care in an HMO population. Medical Care, 28(3), 261-270.

Halpern, J. (2003). What is clinical empathy? Journal of General Internal Medicine, 18(8), 670674. doi: 10.1046/j.1525-1497.2003.21017.x

Hammond, W.P., Matthews, D., Mohottige, D., Agyemang, A. \& Cirbie-Smith, G. (2010). Masculinity, medical mistrust, and preventive health services delays among communitydwelling African-American men. Journal of General Internal Medicine, 25(12), 13001308. doi: 10.1007/s11606-010-1481-z.

Harju, B.L., Wuensch, K.L., Kuhl, E.A., \& Cross, N.J. (2006). Comparison or rural and urban residents' implicit and explicit attitudes related to seeking medical care. Journal of Rural Health, 22(4), 359-363. doi: 10.1111/j.1748-0361.2006.00058.x 
Hoff, R.A., Bruce, M.L., Kasl, S.V., \& Jacobs, S.C. (1997). Subjective ratings of emotional health as a risk factor for major depression in a community sample. The British Journal of Psychiatry, 170, 167-172. doi: 10.1192/bjp.170.2.167.

Hojat, M., Louis, D.Z., Maxwell, K., Markham, F., Wender, R., \& Gonnella, J.S. (2011). A brief instrument to measure patients' overall satisfaction with primary care physicians. Family Medicine, 43(6), 412-417.

Hojat, M., Louis, D.Z., Maxwell, K., Markham, F., Wender, R., \& Gonnella, J.S. (2010). Patient perception of physician empathy, satisfaction with physician, interpersonal trust, and compliance. International Journal of Medical Education, 1, 83-87. doi: $10.5116 /$ ijme.4d00.b701

Ionescu-Ittu, R., Ciampi, A., Roberge, D., \& Pineault, R. (2007). Continuity of primary care and emergency department utilization among older people. Canadian Medical Association Journal, 177(11), 1362- 1368. doi: 10.1503/cmaj.061615

Jang, Y., Park, N. S., Kim, G., Kwag, K.H., Roh, S., \& Chiriboga, D.A. (2012). The association between self-rated mental health and symptoms of depression in Korean American older adults. Aging Mental Health. 16(4), 481-485. doi: 10.1080/13607863.2011.628981.

John, O. P., \& Srivastava, S. (1999). Big Five Inventory (Bfi). Handbook of Personality: Theory and Research, 2, 102-138. http://doi.org/10.1525/fq.1998.51.4.04a00260

Jylhä, M. (2009). What is self-rated health and why does it predict mortality? Toward a unified conceptual model. Social Science and Medicine, 69, 307-316. doi: 10.1016/j.socscimed.2009.05.013

Julliard, K., Vivar, J., Delgardo, C., Cruz, E., Kabak, J., \& Sabers, H. (2008). What Latina patients don't tell their doctors: A qualitative study. Annals of Internal Medicine, 
6(6), 543-549. doi: 10.1370/afm.912

Kane, G.C., Gotto, J.L., Mangione, S., West, S., \& Hojat, M. (2007). Jefferson Scale of Patient's Perceptions of Physician Empathy: Preliminary psychometric data. Croatian Medical Journal, 48(1), 81-86.

Kao, A., Green, D. , Zaslavsky, A., Koplan, J., \& Cleary, P. (1998) The relationship between method of physician payment and patient trust. The Journal of the America Medical Association. 280(19), 1708-1714. doi: 10.1001/jama.280.19.1708

Kelly, J.M., Kraft-Todd, G., Schapira, K., Kossowky, J., \& Reiss, H. (2014). The influence of the patient-clinician relationship on healthcare outcomes: A systematic review and meta-analysis of randomized controlled trials. PLoS One, 9(4), 1-7. doi: 10.1371/journal.pone.0094207

Kraetschmer, N., Sharpe, N., Urowitz, S,. \& Deber, R.B. (2004). How does trust affect patient preferences for participation in decision-making? Health Expect, 7(4), 317-326. doi: 10.1111/j.1369-7625.2004.00296.x

Kong, M.C., Camacho, F. T., Feldman, S.R., Anderson, R. T., \& Balkrishnan, R. (2007). Correlates of patient satisfaction with physician visit: Differences between elderly and non-elderly survey respondents. Health and Quality of Life Outcomes. 5(62), 11-18. doi: 10.1186/1477-7525-5-62

LaVeist, T.A., Nickerson, K.J, \& Bowie, J.V. (2000). Attitudes about racism, medical mistrust, and satisfaction with care among African American and White cardiac patients. Medical Care Research Review, 57, 146-161.

Lee, E.O. \& Emanuel, E.J. (2013). Shared decision making to improve care and reduce costs. The New England Journal of Medicine, 6-8. doi: 10.1056/NEJMp1209500 
Lemaster, P., Pichayayothin, N., \& Strough, J. (2015). Using Amazon's Mechanical Turk to recruit older adults: Easy and cheap, bit is it valid? The Gerontologist, 55(2), 469.

Little, R. J. A. (1986). A test of missing completely at random for multivariate data with missing values. Journal of the American Statistical Association, 83, 1198-1202.

Mainous, A.G., Baker, R., Periera Gray, D., \& Gill, J. M.R. (2001). Continuity of care and trust in one's physician: Evidence from primary care in the United States and the United Kingdom. Family Medicine, 33(1), 22-27.

Maly, R.C., Stein, J.A., Umezawa, Y., Leake, B., \& Anglin, M.D. (2009). Racial/ ethnic differences in breast cancer outcomes among older patients: Effects of physician communication and patient empowerment. Health Psychology, 27(6), 728-736. doi: $10.1037 / 0278-6133.27 .6 .728$

Mason, W. \& Suri, S. (2012). Conducting behavioral research on Amazon's Mechanical Turk. Behavior Research Methods, 44, 1-23. doi: 10.3758/s13428-011-0124-6

Mayer, R.C., Davis, J.H., \& Schoorman, F.D. (1995). An integrative model of organizational trust. The Academy of Management Review, 20(3), 709-734.

Mechanic, D. (1996). Changing medical organizations and the erosion of trust. The Milbank Quarterly, 74(2), 171-189.

Mechanic, D. \& Schlesinger, M. (1996). The impact of managed care on patients' trust in medical care and their physicians. The Journal of the America Medical Association. 275(21), 1693-1697.

Miller, L.C., Berg, J.H. \& Archer, R.L. (1983). Openers: Individuals who elicit intimate selfdisclosure. Journal of Personality and Social Psychology, 44(6), 1234-1244. doi: $10.1037 / 0022-3514.44 .6 .1234$ 
Mishra, A.K. (1996). Organizational responses to crisis: The centrality of trust. In R.M. Kramer \& T. Tyler (Ed.), Trust in Organizations. (pp. 261-287). Newbury Park, CA: Sage.

Mollborn, S., Stepanikova, I., \& Cook, K. S. (2005). Delayed care and unmet needs among health care system users: When does fiduciary trust in a physician matter? Health Services Research, 40(6), 1898-1917. doi: 10.1111/j.1475-6773.2005.00457.x

Muller, E., Zill, J.M., Dirmair, J., Harter, M., \& Scholl, I. (2014). Assessment of trust in physician: A systematic review of measures. PLoS One, 9(9), 1-9. doi: 10.1371/journal.pone.0106844

Musa, D., Schultz, R., Harris, R., Silverman, M., \& Thomas, S.B. (2009). Trust in the health care system and the use of preventive health care services by older black and white adults. American Journal of Public Health, 99(7), 1293- 1299. doi: 10.2105/AJPH.2007.123927

Nicholas, J., \& Hall, W. (2012). Screening and preventive services for older adults. The Mount Sinai Journal of Medicine, 78(4), 498-508. doi: 10.1002/msj.20275

Nunnaly, J.C. (1978). Psychometric Theory. New York: McGraw-Hill.

O'Malley, A.S., Sheppard, V.B., Schwartz, M., \& Mandelblatt, J. (2004). The role of trust in use of preventive services among low-income African-American women. Preventive Medicine, 38, 777-785.

Paolacci, G., \& Chandler, J. (2014). Inside the turk: Understanding Mechanical Turk as a participant pool. Current Directions in Psychological Science, 23, 184-188. doi: $10.1177 / 0963721414531598$ 
Pearson, S. \& Raeke, L. (2000). Patients' trust in physicians: Many theories, few measures, and little data. Journal of General Internal Medicine. 15(7), 509-513. doi: 10.1046/j.1525-1497.2000.11002.x

Peek, M.E., Gorawara-Bhat, R., Quinn, M.T., Odoms-Young, A., Wilson, S.C., \& Chin, M.H. (2013). Patient trust in physicians and share decision-making among African Americans with diabetes. Journal of Health Communication, 28(6), 616-623. doi: $10.1080 / 10410236.2012 .710873$

Piette, J.D., Heilser, M., \& Krein, S. (2005). The role of patient-physician trust in moderating medication nonadherence due to cost pressures. JAMA Internal Medicine, 165(15), 1749-1755. doi: 10.1001/archinte.165.15.1749

Platonova, E.A., Kennedy, K.N. \& Shewchuk, R.M. (2008). Understanding patient satisfaction, trust, and loyalty to primary care physicians. Medical Care Research and Review: 65(6), 696-712. doi: $10.1177 / 1077558708322863$

Podsakoff, P. M., MacKenzie, S. B., Lee, J. Y., \& Podsakoff, N. P. (2003). Common method biases in behavioral research: A critical review of the literature and recommended remedies. Journal of Applied Psychology, 88, 879-903.

Poulin, M. J., \& Haase, C. M. (2015). Growing to trust: Evidence that trust increases and sustains well-being across the life span. Social Psychological and Personality Science, 6, 614621. doi: $10.1177 / 1948550615574301$

Rickwood, D., Deane, F., \& Wilson, C. (2007). When and how do young people seek professional help for mental health problems?. The Medical Journal of Australia, 187(7), S35-39.

Robinson, J.P., Shaver, P.R., \& Wrightsman, L.S. (Eds). Measures of personality 
and social psychological attitudes. San Diego: Academic Press

Rosenberg, M. (1957). Organizations and values (pp. 25-35). Glencoe, IL: Free Press. Robinson, J. P., Shaver, P. R., \& Wrightsman, L. S. (1991). Measures of personality and social psychological attitudes (pp. 404-406). San Diego: Academic Press.

Rotter, J.B. (1980). Interpersonal trust, trustworthiness, and gullibility. American Psychologist, $35(1), 1-7$.

Safran, D., Kosinski, M., Tarlov, A., Rogers, W., Taira, D., Lieverman, N., \& Ware, J. (1998) The Primary Care Assessment Survey: Tests of data quality and measurement performance. Medical Care 36(5), 728-739.

Sepucha, K.R., Fagerlin, A., Couper, M.P., Levin, C.A., Singer, E., \& Zikmund-Fisher, B.J. (2010). How does feeling informed relate to being informed? The DECISIONS survey. Medical Decision Making, 77-84. doi: 10.1177/0272989X10379647.

Siminoff, L. A., Hausmann, L. R., \& Ibrahim, S. (2008). Barriers to obtaining diagnostic testing for coronary artery disease among veterans. American Journal of Public Health, 98(12), 2207-2213. doi: 10.2105/AJPH.2007.123224

Spies, C.D., Schultz, C.M., Weiss-Gerlach, E., Neuner, B., Neumann, T., von Dossow, V., Schenk, M., Wernecke, K.D., \& Elwyn, G. (2006). Preferences for shared decisionmaking in chronic pain patients compared with patients during a premedication visit. Acta Anaesthesiologica Scandinavica, 50(8), 1019-1026.

doi: 10.1111/j.1399-6576.2006.01097.x

Stacey, D., Legara, Nf, C., Cl, B., Mj, B., Kb, E., ...Holmes-rovner, M. (2014). Decision aids for 
people facing health treatment or screening decisions (Review) Decision aids for people facing health treatment or screening decisions. The Cochrane Database of Systematic Reviews. doi: 10.1002/14651858.CD001431.pub4.Copyright

Suchman, A.L., Markakis, K., Beckman, H.B., \& Frankel, R. (1997). A model of empathetic communication in the medical interview. JAMA, 277(8), 678-682.

Sung, V.W., Raker, C.A., Myers, D.L. \& Clark, M.A. (2010). Treatment decision-making and information-seeking preferences in women with pelvic floor disorders. International Urogynecology Journal, 21(9), 1071-1078. doi: 10.1007/s00192-010-1155-8

Tabachnick, B. G., and Fidell, L. S. (2012). Using Multivariate Statistics, 6th ed. Boston: Pearson.

Thom, D., Hall, M.A. \& Pawlson, G.L. (2004) Measuring Patients' Trust in Physicians When Assessing Quality of Care. Health Affairs. 23(4), 124-132. doi: 10.1377/hlthaff.23.4.124.

Thom, D., Kravitz, R., Bell, R., Krupat, E., \& Azari, R. (2002). Patient trust in physician: relationship to patient requests. Family Practice. 19(5), 476-483.

Thom, D., Ribisl, K., Stewart, A., \& Luke, D. (1999) Further validation and reliability testing of the trust in physician scale. Medical Care. 37(5), 510-517.

Trachtenberg, F., Dugan, E., \& Hall, M.A. (2005). How patients' trust relates to their involvement in medical care. The Journal of Family Practice. 54(4), 344-352.

Trust. (n.d.). Retrieved April 4, 2017, from https://www.merriam-webster.com/dictionary/trust.

Tulsky, J.A., Arnold, R.M., Alexander, S.C., Olsen, M.K., Jefferys, A.S., Rodriguez, K.L., Skinner, C.S., Farrell, D., Abernathy, A.P., \& Pollak, K.I. (2011). Enhancing communication between oncologists and patients with a computerized-based training program: A randomized trial. Annals of Internal Medicine, 155(9), 593-601. 
doi: 10.7326/0003-4819-155-9-201111010-00007

van den Berk-Clark, C. \& McGuire, J. (2014). Trust in health care providers: Factors predicting trust in homeless veterans over time. Journal of Healthcare for the Poor and Underserved, 25(3), 1278-1290. doi: 10.1353/hpu.2014.0115.

Wallston, K. A., Strudler Wallston, B., \& DeVellis, R. (1978). Development of the multidimensional health locus of control (MHLC) scales. Health Education \& Behavior, $6(1), 160-170$.

Wallston KA. (2005). The validity of the multidimensional health locus of control scales. Journal of Health Psychology, 10, 623-631. doi: 10.1177/1359105305055304

Ware, J.E.\& Sherbourne, C.D. (1992). The MOS 36-item Short Form Health Survey (SF-36): Conceptual framework and item selection. Medical Care, 30(6), 473-483.

Weng, H.C. (2008). Does the physician's emotional intelligence matter? Impacts of physician's emotional intelligence on trust, patient-physician relationship, and satisfaction. Health Care Management Review, 33(4), 280-288. doi: 10.1097/01.HCM.0000318765.52148.b3

Winefield, H.R. (1982). Reliability and validity of the health locus of control scale. Journal of Personality Assessment, 46(6), 614-619.

Zajacova, A. \& Dowd, J.B. (2011). Reliability of Self-rated health in US Adults. American Journal of Epidemiology, 174(8), 977-983. doi: 10.1093/aje/kwr204

Zheng, B., Hall, M.A., Dugan, E., Kidd, K.E. \& Levine, D. (2002). Development of a scale to measure patients' trust in health insurers. Health Services Research Journal, 37(1), 185-200. doi: 10.1111/1475-6773.00145 
Table 1

Sample Characteristics

Measure
Age (M)
Gender
Male
Female
Race/Ethnicity
White/Caucasian, not Hispanic
Black or African American
Hispanic or Latino/Latina
Native American or Native Alaskan
Asian or Pacific Islander
Other or multi-racial
Education
GED/ High school diploma
Some college
College
Postgraduate
Other

\begin{tabular}{llll}
\multicolumn{2}{c}{ Young adults } & \multicolumn{2}{c}{ Older adults } \\
$\mathrm{n}$ & $\% / \mathrm{SD}$ & $\mathrm{n}$ & $\% / \mathrm{SD}$ \\
35.31 & 9.65 & 67.86 & 3.12 \\
& & & \\
89 & $49.7 \%$ & 80 & $49.7 \%$ \\
89 & $49.7 \%$ & 81 & $50.3 \%$ \\
& & & \\
133 & $74.3 \%$ & 124 & $77.5 \%$ \\
15 & $8.4 \%$ & 18 & $11.2 \%$ \\
13 & $7.3 \%$ & 10 & $6.3 \%$ \\
14 & $7.8 \%$ & 15 & $3.1 \%$ \\
2 & $1.1 \%$ & 1 & $0.6 \%$ \\
2 & $1.1 \%$ & 2 & $1.3 \%$ \\
& & & \\
17 & $9.5 \%$ & 19 & $11.8 \%$ \\
53 & $29.6 \%$ & 41 & $25.5 \%$ \\
93 & $52.0 \%$ & 80 & $49.7 \%$ \\
15 & $8.4 \%$ & 20 & $12.4 \%$ \\
0 & 0 & 1 & $0.6 \%$
\end{tabular}


Table 2

Pearson Product Correlations for Sample of Young Adults ( $n=179)$

\begin{tabular}{|c|c|c|c|c|c|c|c|c|c|c|c|c|}
\hline Variables & $M(S D)$ & 1 & 2 & 3 & 4 & 5 & 6 & 7 & 8 & 9 & 10 & 11 \\
\hline 1. WFPTS & $35.87(6.12)$ & -- & $.248^{* *}$ & $.768^{* *}$ & $.791^{* *}$ & $.224^{* *}$ & $.241^{* *}$ & -.125 & $.220^{* *}$ & -.109 & $.516^{* *}$ & -.086 \\
\hline 2. PHNT & $53.49(10.79)$ & & -- & $.231^{* *}$ & $.172^{*}$ & $.229^{*}$ & .051 & $-.218^{* *}$ & .060 & $.313^{* *}$ & $.225^{* *}$ & .099 \\
\hline 3. JSPPPE & $24.90(6.72)$ & & & -- & $.823^{* *}$ & $.183^{* *}$ & $.273^{* *}$ & $-.182^{*}$ & $.286^{* *}$ & $.268^{* *}$ & $.470 * *$ & -.111 \\
\hline 4. PSS & $52.05(9.40)$ & & & & -- & $.296^{* *}$ & $.291^{* *}$ & $-.174^{*}$ & .127 & $.317^{* *}$ & $.508^{* *}$ & -.126 \\
\hline 5. API & $51.18(4.94)$ & & & & & -- & .036 & -.116 & .120 & .139 & $.254^{* *}$ & $.199 * *$ \\
\hline 6. IHLC & $25.18(4.57)$ & & & & & & -- & $-.335^{* *}$ & .035 & $.186^{*}$ & .077 & -.138 \\
\hline 7. CHLC & $19.45(5.47)$ & & & & & & & -- & $.262^{* *}$ & $-.148^{*}$ & -.090 & .013 \\
\hline 8. PHLC & $19.20(5.36)$ & & & & & & & & -- & -.030 & .048 & -.152 \\
\hline 9. IPIP_O & $11.22(4.62)$ & & & & & & & & & -- & $.168^{*}$ & -.045 \\
\hline 10. Con. & $4.32(0.78)$ & & & & & & & & & & -- & -.010 \\
\hline 11. Health & $2.02(0.67)$ & & & & & & & & & & & -- \\
\hline
\end{tabular}

$* p<.05, * * p<.01$

WFPTS = Wake Forest Physician Trust Scale; PHNT = Philosophies of Human Nature- Trustworthiness; JSPPPE = Jefferson Scale of Patient Perception of Physician Empathy; PSS = Patient Satisfaction Scale; API = Autonomy Preference Index; IHLC = Multidimensional Health Locus of Control Scale Form A (MHLC) Internal Health Locus of Control subscale; CHLC = MHLC Chance Health Locus of Control subscale; PHLC = MHLC Powerful Others Externality; IPIP_O = MINI- International Personality Item Pool Openness subscale; Con. $=$ Confidentiality; Health $=$ Self-Rated Health 
Table 3

Pearson Product Correlations for Sample of Older Adults $(n=161)$

\begin{tabular}{|c|c|c|c|c|c|c|c|c|c|c|c|c|}
\hline Variables & $M(S D)$ & 1 & 2 & 3 & 4 & 5 & 6 & 7 & 8 & 9 & 10 & 11 \\
\hline 1. WFPTS & $36.12(6.11)$ & -- & $.378^{* *}$ & $.764^{* *}$ & $.775^{* *}$ & $.366^{* *}$ & $.286^{* *}$ & .036 & $.204^{* *}$ & -.167 & $.306^{* *}$ & $-.194^{*}$ \\
\hline 2. PHNT & $53.44(10.74)$ & & -- & $.329 * *$ & $.336^{* *}$ & $.174^{*}$ & .102 & $-.257^{* *}$ & .042 & -.133 & $.222^{* *}$ & $-.229 * *$ \\
\hline 3. JSPPPE & $26.50(6.10)$ & & & -- & $.861^{* *}$ & $.378^{* *}$ & $.367^{* *}$ & .068 & $.287^{* *}$ & $.296^{* *}$ & $.368^{* *}$ & $-.212^{* *}$ \\
\hline 4. PSS & $52.37(8.85)$ & & & & -- & $.426^{* *}$ & $.325^{* *}$ & .008 & $.220^{* *}$ & $.273^{* *}$ & $.409 * *$ & $-.163^{*}$ \\
\hline 5. API & $50.24(5.75)$ & & & & & -- & .145 & .033 & $.194^{*}$ & .134 & $.272^{* *}$ & -.090 \\
\hline 6. IHLC & $25.84(4.55)$ & & & & & & -- & -.079 & .144 & $.262^{* *}$ & $.182^{*}$ & $-.170 *$ \\
\hline 7. CHLC & $19.58(5.66)$ & & & & & & & -- & $.518^{* *}$ & $-.356^{* *}$ & -.095 & .121 \\
\hline 8. PHLC & $20.92(6.12)$ & & & & & & & & -- & $-.194 *$ & .026 & .119 \\
\hline 9. IPIP_O & $12.74(4.53)$ & & & & & & & & & -- & $.249 * *$ & $-.359 * *$ \\
\hline 10. Con. & $4.27(.0 .93)$ & & & & & & & & & & -- & -.068 \\
\hline 11. Health & $2.08(0.72)$ & & & & & & & & & & & -- \\
\hline
\end{tabular}

${ }^{*} p<.05,{ }^{* *} p<.01$

WFPTS = Wake Forest Physician Trust Scale; PHNT = Philosophies of Human Nature- Trustworthiness; JSPPPE = Jefferson Scale of Patient Perception of Physician Empathy; PSS = Patient Satisfaction Scale; API = Autonomy Preference Index; IHLC = Multidimensional Health Locus of Control Scale Form A (MHLC) Internal Health Locus of Control subscale; CHLC = MHLC Chance Health Locus of Control subscale; PHLC = MHLC Powerful Others Externality; IPIP_O = MINI- International Personality Item Pool Openness subscale; Con. $=$ Confidentiality; Health $=$ Self-Rated Health 
Table 4

Reliability Coefficients

Cronbach's alpha

Average inter-item correlation coefficients
Young adults

.802

.358
Older adults

.799

.362 
Appendix A: Demographics

This next section will ask you general questions about yourself.

1. What is your age?

2. What is your biological sex?
a. Male
b. Female

3. What is your race or ethnic background? (please choose one):
a. White/Caucasian (not Hispanic)
b. Black/African-American
c. Asian-American
d. Hispanic
e. Native American
f. Pacific Islander
g. Other

4. Please specify if you selected Other as your answer for question \#3.

5. What is the highest level of education you completed?
a. GED/High school diploma
b. Some college
c. College
d. Postgraduate
e. Other

6. Please specify if you selected Other as your answer for question \#6.

7. What is your marital status?
a. Single
b. Married
c. Live-in partner
d. Separated
e. Divorced
f. Widowed

8. What is your current job or occupation status?
a. Working full time (for income or as volunteer)
b. Working part time (for income or as volunteer)
c. Retired
d. Other

9. Please specify if you selected Other as your answer for question \#8.

10. What year were you born? 


\section{Appendix B: Wake Forest Trust in Physicians Scale}

"Please indicate to what extent you trust the physicians on a scale from 1 (strongly disagree) to 5 (strongly agree)."

\begin{tabular}{|l|l|l|l|l|l|}
\hline & $\begin{array}{l}\text { Strongly } \\
\text { Disagree } \\
\text { (1) }\end{array}$ & Disagree & Neutral & Agree & $\begin{array}{c}\text { Strongly } \\
\text { Agree } \\
\text { (2) }\end{array}$ \\
\hline $\begin{array}{l}\text { Your doctor will do whatever it takes } \\
\text { to get you all the care you need. }\end{array}$ & & & & & \\
\hline $\begin{array}{l}\text { Sometimes your doctor cares more } \\
\text { about what is convenient for him/her } \\
\text { than about your medical needs. }\end{array}$ & & & & & \\
\hline $\begin{array}{l}\text { Your doctor's medical skills are not as } \\
\text { good as they should be. }\end{array}$ & & & & & \\
\hline $\begin{array}{l}\text { Your doctor is extremely thorough } \\
\text { and careful. }\end{array}$ & & & & & \\
\hline $\begin{array}{l}\text { You completely trust your doctor's } \\
\text { decisions about which medical } \\
\text { treatments are best for you. }\end{array}$ & & & & & \\
\hline $\begin{array}{l}\text { Your doctor is totally honest in telling } \\
\text { you about all of the different } \\
\text { treatment options available for your } \\
\text { condition. }\end{array}$ & & & & & \\
\hline $\begin{array}{l}\text { Your doctor only thinks about what is } \\
\text { best for you. }\end{array}$ & & & & & \\
\hline $\begin{array}{l}\text { Sometimes your doctor does not pay } \\
\text { full attention to what you are trying to } \\
\text { tell him/ her. }\end{array}$ & & & & & \\
\hline $\begin{array}{l}\text { You have no worries about putting } \\
\text { your life in your doctor's hands. }\end{array}$ & & & & & \\
\hline $\begin{array}{l}\text { All in all, you have complete trust in } \\
\text { your doctor. }\end{array}$ & & & & & \\
\hline
\end{tabular}

Note. Measure from Hall et al., (2001). 
Appendix C: Philosophies of Human Nature: Trustworthiness Subscale.

Instructions: Here is a series of attitude statements. Each represents a commonly held opinion and there are no right or wrong answers. You will probably disagree with some items and agree with others. We are interested in the extent to which you agree or disagree with such matters of opinion. Read each statement carefully. Then indicate the extent to which you agree or disagree.

$\begin{array}{llllll}-3 & -2 & -1 & +1 & +2 & +3 \\ \text { Disagree } & \text { Disagree } & \text { Disagree } & \text { Agree } & \text { Agree } & \text { Agree } \\ \text { strongly } & \text { somewhat } & \text { slightly } & \text { slightly } & \text { somewhat } & \text { strongly }\end{array}$

1. Most students will tell the instructor when he or she had made a mistake in adding up their score, even if the instructor had given them more points than they deserved.

2. If you give the average person a job to do and leave him or her to do it, the person will finish it successfully.

3. People usually tell the truth, even when they know they would be better off lying.

4. Most people do not cheat when taking an exam.

5. Most people are basically honest.

6. People claim they have ethical standards regarding honesty and morality, but few people stick to them when the chips are down.

7. If you want people to do a job right, you should explain things to them in great detail and supervise them closely.

8. If most people could get into a movie without paying and be sure they were not seen, they would do it.

9. Most people are not really honest for a desirable reason; they're afraid of getting caught.

10. Most people would tell a lie if they could gain by it.

11. If you act in good faith with people, almost all of them will reciprocate with fairness towards you.

12. Most people would cheat on their income tax, if they had a chance.

13. Most people lead clean, decent lives.

14. Nowadays people commit a lot of crimes that no one else ever hears about.

Note. Measure from Wrightsman, (1964). 


\section{Appendix D: Jefferson Scale of Patient Perceptions of Physician Empathy}

Instructions: We would like to know the extent of your agreement or disagreement with each of the following statements about your physician named below. Please use the following 7-point scale and write your rating number from 1 to 7 on the underlined space before each statement (1 means that you Strongly Disagree, and 7 means you Strongly Agree with the statement, a higher number indicates more agreement).

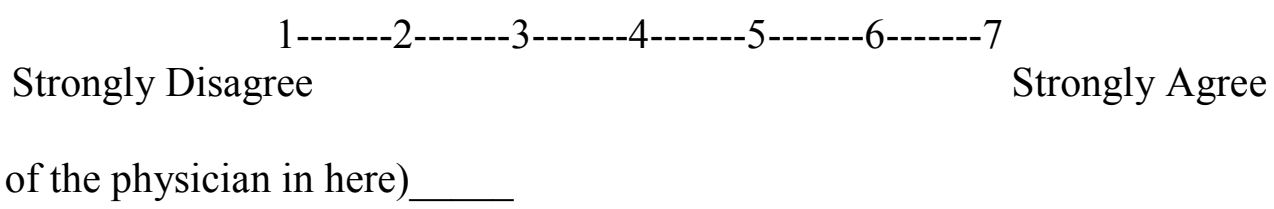

1. Can view things from my perspective (see things as I see them).

2. - Asks about what is happening in my daily life.

3. _ Seems concerned about me and my family.

4. _ Understands my emotions, feelings and concerns.

5. _ Is an understanding doctor.

Note. Measure from Kane et al., (2007). 
Appendix E: Patient Satisfaction Scale

Instructions: We would like to know the extent of your agreement or disagreement with each of the following statements about your physician.

Strongly Disagree 1------2-------3------4------5------6------7

1. I am satisfied that my doctor has been taking care of me.

2. My doctor explains the reason(s) for any medical test.

3. My doctor explains things in a way that is easy for me to understand.

4. I am confident of my doctor's knowledge and skills.

5. My doctor shows respect to what I have to say.

6. My doctor listens carefully to me.

7. My doctor really cares about me as a person.

8. My doctor encourages me to talk about all my health concerns.

9. My doctor spends enough time with me.

10. I would like my doctor to be present in any medical emergency situation.

Note. Measure from Hojat et al., (2011). 
Appendix F: The Autonomy Preference Index

1. Decision making preference scale.

A. General items.

\begin{tabular}{|c|c|c|c|c|c|}
\hline & $\begin{array}{l}\text { Strongly } \\
\text { Disagree }\end{array}$ & Disagree & $\begin{array}{l}\text { Neither } \\
\text { Agree or } \\
\text { Disagree }\end{array}$ & Agree & $\begin{array}{c}\text { Strongly } \\
\text { Agree }\end{array}$ \\
\hline $\begin{array}{l}\text { The important medical decisions } \\
\text { should be made by your doctor, not by } \\
\text { you. }\end{array}$ & 1 & 2 & 3 & 4 & 5 \\
\hline $\begin{array}{l}\text { You should go along with your } \\
\text { doctor's advice even if you disagree } \\
\text { with it. }\end{array}$ & 1 & 2 & 3 & 4 & 5 \\
\hline $\begin{array}{l}\text { When hospitalized, you should not be } \\
\text { making decisions about your own } \\
\text { care. }\end{array}$ & 1 & 2 & 3 & 4 & 5 \\
\hline $\begin{array}{l}\text { You should feel free to make } \\
\text { decisions about everyday medical } \\
\text { problems. }\end{array}$ & 1 & 2 & 3 & 4 & 5 \\
\hline $\begin{array}{l}\text { If you were sick, as your illness } \\
\text { became worse you would want your } \\
\text { doctor to take greater control. } \\
\text { You should decide how frequently }\end{array}$ & 1 & 2 & 3 & 4 & 5 \\
\hline you need a check up. & 1 & 2 & 3 & 4 & 5 \\
\hline
\end{tabular}

Suppose you developed a sore throat, stuffy nose, and cough that lasted for three days. You are about to call your doctor on the telephone. Who should make the following decisions?

\begin{tabular}{lccccc}
\hline & $\begin{array}{l}\text { You } \\
\text { alone }\end{array}$ & $\begin{array}{l}\text { Mostly } \\
\text { you }\end{array}$ & $\begin{array}{l}\text { The } \\
\text { doctor } \\
\text { and you } \\
\text { equally. }\end{array}$ & $\begin{array}{l}\text { Mostly } \\
\text { the } \\
\text { doctor. }\end{array}$ & $\begin{array}{l}\text { The } \\
\text { doctor } \\
\text { alone. }\end{array}$ \\
\hline $\begin{array}{l}\text { Whether you should be seen by the } \\
\text { doctor. }\end{array}$ & 1 & 2 & 3 & 4 & 5 \\
$\begin{array}{l}\text { Whether a chest x-ray should be } \\
\text { taken. }\end{array}$ & 1 & 2 & 3 & 4 & 5 \\
$\begin{array}{l}\text { Whether you should try taking cough } \\
\text { syrup. }\end{array}$ & 1 & 2 & 3 & 4 & 5
\end{tabular}


Suppose you went to your doctor for a routine physical examination and he or she found that everything was all right except that your blood pressure was high (170/100). Who should make the following decisions?

\begin{tabular}{lccccc}
\hline & $\begin{array}{l}\text { You } \\
\text { alone }\end{array}$ & $\begin{array}{l}\text { Mostly } \\
\text { you }\end{array}$ & $\begin{array}{l}\text { The } \\
\text { doctor } \\
\text { and you } \\
\text { equally. }\end{array}$ & $\begin{array}{l}\text { Mostly } \\
\text { the } \\
\text { doctor. }\end{array}$ & $\begin{array}{l}\text { The } \\
\text { doctor } \\
\text { alone. }\end{array}$ \\
\hline $\begin{array}{l}\text { When the next visit to check your } \\
\text { blood pressure should be. }\end{array}$ & 1 & 2 & 3 & 4 & 5 \\
$\begin{array}{l}\text { Whether you should take some time } \\
\text { off work to relax. }\end{array}$ & 1 & 2 & 3 & 4 & 5 \\
$\begin{array}{l}\text { Whether you should be treated with } \\
\text { medication or diet. }\end{array}$ & 1 & 2 & 3 & 4 & 5
\end{tabular}

Suppose you had an attack of severe chest pain that lasted for almost an hour, frightening you enough so that you went to the emergency room. In the emergency room the doctors discovered you were having a heart attack. Your own doctor is called and you are taken up to the intensive care unit. Who should make the following decisions?

\begin{tabular}{lccccc}
\hline & $\begin{array}{l}\text { You } \\
\text { alone }\end{array}$ & $\begin{array}{l}\text { Mostly } \\
\text { you }\end{array}$ & $\begin{array}{l}\text { The } \\
\text { doctor } \\
\text { and you } \\
\text { equally. }\end{array}$ & $\begin{array}{l}\text { Mostly } \\
\text { the } \\
\text { doctor. }\end{array}$ & $\begin{array}{l}\text { The } \\
\text { doctor } \\
\text { alone. }\end{array}$ \\
\hline $\begin{array}{l}\text { How often the nurses should wake } \\
\text { you up to check your temperature and } \\
\text { blood pressure. }\end{array}$ & 1 & 2 & 3 & 4 & 5 \\
$\begin{array}{l}\text { Whether you may have visitors aside } \\
\text { from your immediate family. }\end{array}$ & 1 & 2 & 3 & 4 & 5 \\
$\begin{array}{l}\text { Whether a cardiologist should be } \\
\text { consulted. }\end{array}$ & 1 & 2 & 3 & 4 & 5
\end{tabular}

Note. Measure from Ende et al., (1989). 
Appendix G: Multidimensional Health Locus of Control Scale Form A

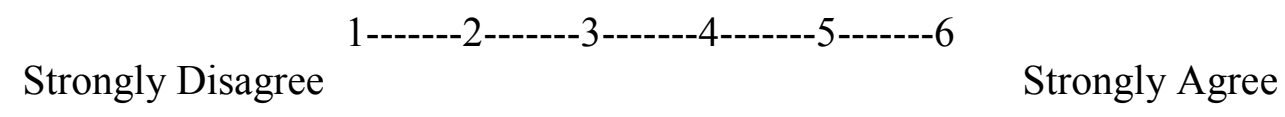

1. If I get sick, it is my own behavior, which determines how soon I will get well again

2. No matter what I do, if I am going to get sick, I will get sick.

3. Having regular contact with my physician is the best way for me to avoid illness.

4. Most things that affect my health happen to me by accident.

5. Whenever I don't feel well, I should consult a medically trained professional.

6. I am in control of my health.

7. My family has a lot to do with my being sick or staying health.

8. When I get sick I am to blame.

9. Luck plays a big part in determining how soon I will recover from an illness.

10. Health professionals control my health.

11. My good health is largely a matter of good fortune.

12. The main things that affects my health is what I myself do.

13. If I take care if myself, I can avoid illness.

14. When I recover from an illness, it's usually because other people (for example, doctors, nurses, family, friends) have been taking good care of me.

15. No matter what I do, I'm likely to get sick.

16. If it's meant to be, I will stay healthy.

17. If I take the right actions, I can stay healthy.

18. Regarding my health, I can only do what my doctor tells me to do.

Note. Measure from Wallston, Wallston, \& DeVellis (1978). 


\section{Appendix H: Mini IPIP}

Describe yourself as you generally are now, not as you wish to be in the future. Describe yourself as you honestly see yourself, in relation to other people you know of the same sex as you are, and roughly your same age. Indicate for each statement whether it is 1. Strongly Agree, 2. Agree, 3. Neither Agree Nor Disagree, 4. Disagree or, 5. Strongly Disagree as a description of you.

IPIP011 I am the life of the party

IPIP021 I sympathize with others' feelings

IPIP031 I get chores done right away

IPIP041 I have frequent mood swings

IPIP051 I have a vivid imagination

IPIP061 I don't talk a lot

IPIP071 I am not interested in other people's problems

IPIP081 I often forget to put things back in their proper place

IPIP091 I am relaxed most of the time

IPIP101 I am not interested in abstract ideas

IPIP111 I talk to a lot of different people at parties

IPIP121 I feel others' emotions

IPIP131 I like order

IPIP141 I get upset easily

IPIP151 I have difficulty understanding abstract ideas

IPIP161 I keep in the background

IPIP171 I am not really interested in others

IPIP181 I make a mess of things

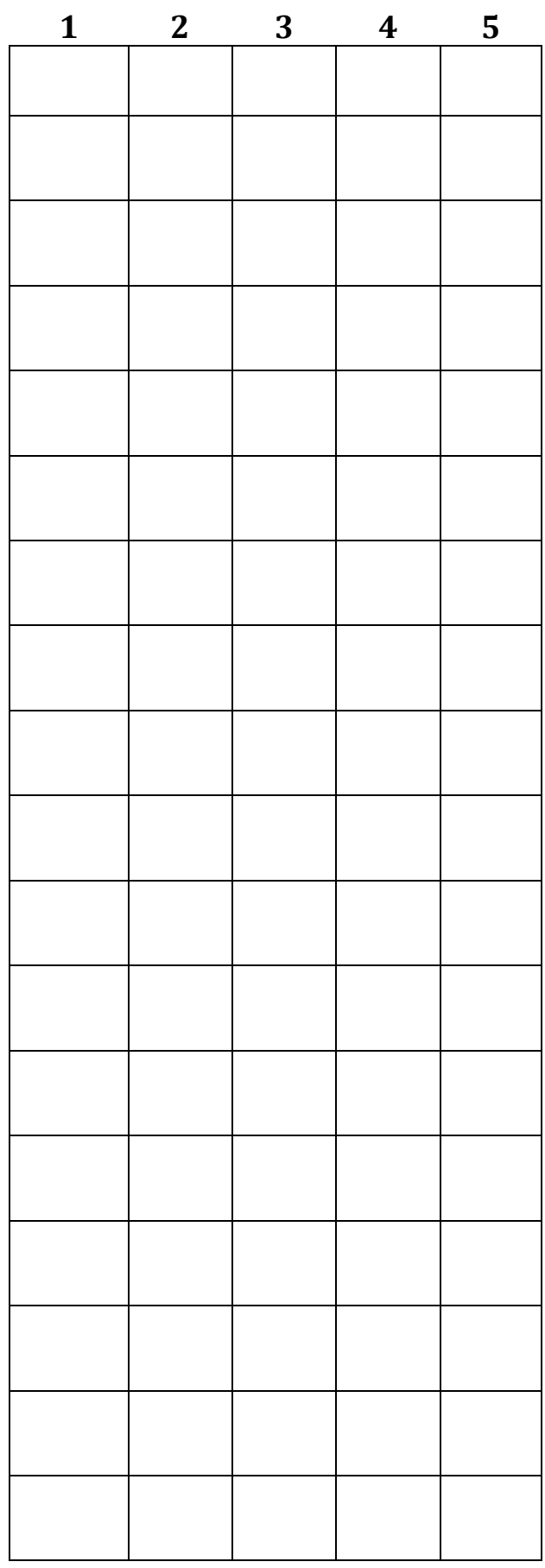


IPIP191 I seldom feel blue

IPIP201 I do not have a good imagination

\begin{tabular}{|l|l|l|l|l|}
\hline & & & & \\
\hline & & & & \\
\hline
\end{tabular}

Note. Measure from Donnellan, Oswald, Baird, \& Lucas (2006). 